\title{
Glucagon-Like Peptide-1 Receptor Agonist Use in People Living with Type 2 Diabetes Mellitus and Chronic Kidney Disease: A Narrative Review of the Key Evidence with Practical Considerations
}

José L. Górriz · Irene Romera • Amelia Cobo • Phillipe D. O’Brien •

Juan F. Merino-Torres

Received: October 7, 2021 / Accepted: December 21, 2021 / Published online: February 17, 2022

(C) The Author(s) 2022

\begin{abstract}
Glucagon-like peptide-1 receptor agonists (GLP1 RAs) are incretin-mimetic agents that are effective adjuncts in the treatment of diabetes. This class of medications is also associated with promoting weight loss and a low risk of hypoglycemia, and some have been shown to be associated with a significant reduction of major cardiovascular events. Mounting evidence suggests that GLP-1 RAs have benefits beyond reducing blood glucose that include improving kidney function in people living with type 2 diabetes mellitus (T2DM) and chronic kidney disease (CKD), a common microvascular complication of T2DM. Several large clinical studies,
\end{abstract}

\section{J. L. Górriz}

Department of Nephrology, Hospital Clínico Universitario de Valencia-INCLIVA, University of Valencia, Valencia, Spain

I. Romera $(\bowtie) \cdot$ A. Cobo

Eli Lilly and Company, Madrid, Spain

e-mail: romera_irene@lilly.com

P. D. O'Brien

Eli Lilly and Company, Little Island, Co. Cork, Ireland

\section{J. F. Merino-Torres}

Endocrinology and Nutrition Department, Hospital Universitario y Politécnico de La Fe, University of

Valencia, Valencia, Spain the majority of which are cardiovascular outcome trials, indicate that GLP-1 RA therapy is safe and tolerable for people living with T2DM and compromised renal function, and also suggest that GLP-1 RAs may have renoprotective properties. Although evidence from clinical trials has shown GLP-1 RAs to be safe and efficacious in people living with T2DM and renal impairment, their use is uncommon in this patient population. With continuing developments in the field of GLP-1 RA therapy, it is important for physicians to understand the benefits and practical use of GLP-1 RAs, as well as the clinical evidence, in order to achieve positive patient outcomes. Here, we review evidence on GLP-1 RA use in people living with T2DM and CKD and summarize renal outcomes from clinical studies. We provide practical considerations for GLP-1 RA use to provide an added benefit to guide treatment in this highrisk patient population.

\section{GRAPHICAL ABSTRACT}


Glucagon-Like Peptide-1 Receptor Agonist Use in People Living with Type 2 Diabetes Mellitus and

Chronic Kidney Disease: A Narrative Review of the Key Evidence with Practical Considerations

José L. Górriz, Irene Romera, Amelia Cobo, Phillipe D. O’Brien, Juan F. Merino-Torres
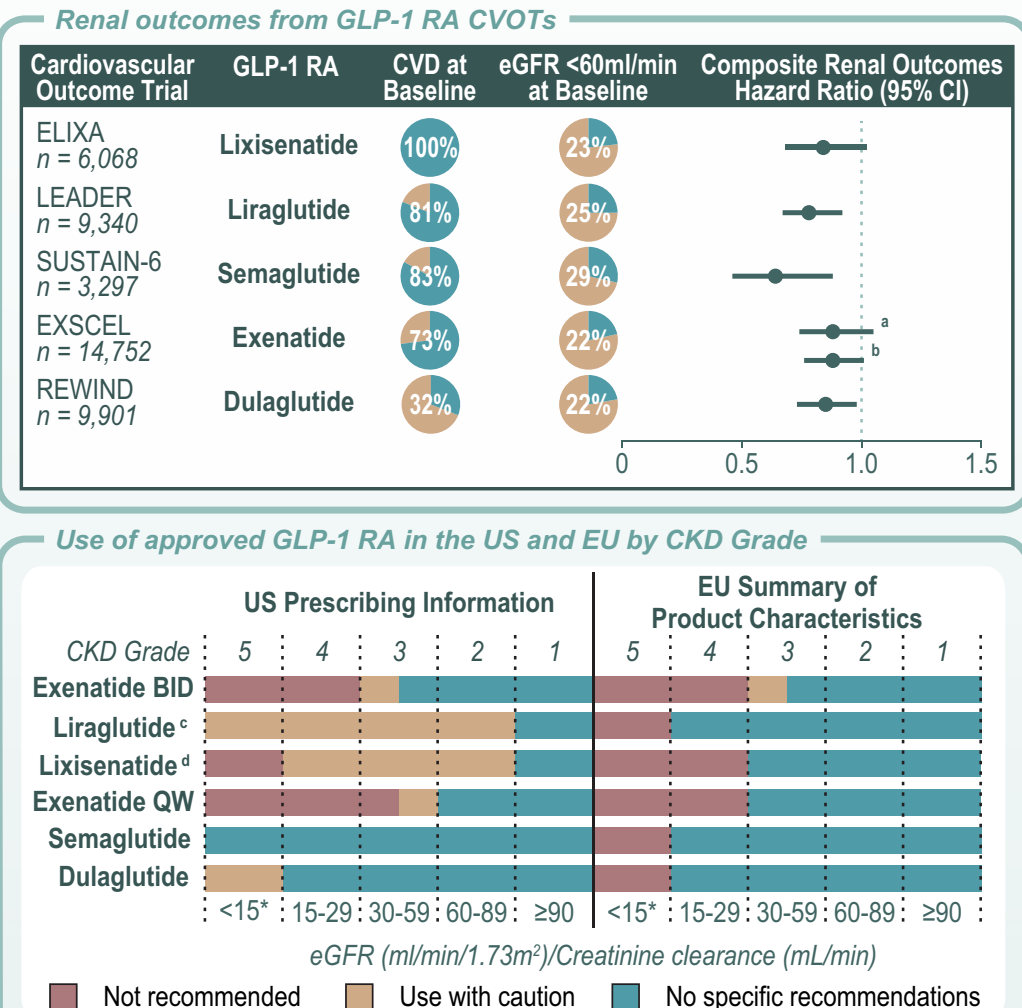

- Frequency and recommended dosages of currently available GLP-1 RAs

\begin{tabular}{|c|c|c|c|}
\hline $\begin{array}{c}\text { Generic name } \\
\text { (Commercial) }\end{array}$ & Frequency & $\begin{array}{c}\text { Initial } \\
\text { Dosage }\end{array}$ & $\begin{array}{c}\text { Recommended } \\
\text { Dosage }\end{array}$ \\
\hline Exenatide BID (Byetta@) & Twice-daily & $5 \mathrm{mcg}$ for 1 month & 5 or $10 \mathrm{mcg}^{f}$ \\
\hline Liraglutide (Victoza@) & Once-daily & $0.6 \mathrm{mg}$ for 1 week & 1.2 or $1.8 \mathrm{mg}$ \\
\hline Lixisenatide (Lyxumia@/Adlyxin@) & Once-daily & $10 \mathrm{mcg}$ for 14 days & $20 \mathrm{mcg}$ \\
\hline Oral semaglutide (Rybelsus@) & Once-daily & $3 \mathrm{mg}$ for 1 month & 7 or $14 \mathrm{mg}$ \\
\hline Exenatide QW (Bydureon@) & Once-weekly & $2 \mathrm{mg}$ & $2 \mathrm{mg}$ \\
\hline Semaglutide (Ozempic@) & Once-weekly & $0.25 \mathrm{mg}$ for 4 weeks & 0.5 or $1 \mathrm{mg}$ \\
\hline Dulaglutide $^{\mathrm{e}}$ (Trulicity@) & Once-weekly & 0.75 or $1.5 \mathrm{mg}$ & $\begin{array}{c}0.75,1.5,3.0 \\
\text { or } 4.5 \mathrm{mg}\end{array}$ \\
\hline
\end{tabular}

No dose adjustment is needed for patients with renal impairment, with the following exception: Caution should be applied when initiating or escalating doses of Byetta from $5 \mathrm{mcg}$ to $10 \mathrm{mcg}$ in patients with moderate renal impairment (creatinine clearance $30-50 \mathrm{~mL} / \mathrm{min}$ ).

Notes: * For the purposes of graphically summarizing the information on GLP-1 RA use in people with renal impairment provided in the US Prescribing Information (USPI) and EU Summary of Product Characteristics (SMPC), end stage renal disease (ESRD) is defined as an eGFR less than 1 $\mathrm{mL} / \mathrm{min} / 1.73 \mathrm{~m}^{2}$. ${ }^{2}$ Renal composite consisting of $40 \%$ eGFR decline, renal replacement, or renal death. ${ }^{\circ}$ Renal composite consisting of eGFR decline

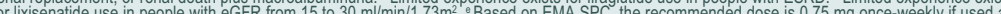
monotherapy and $1.5 \mathrm{mg}$ once-weekly if used as an add-on therapy. The initial dose for dulaglutide is $0.75 \mathrm{mg}$, as indicated in the FDA-approved labe for Trulicity. The EMA Summary of Product Characteristics (SPC) recommends a dose of 5 or $10 \mathrm{mcg}$ for exenatide twice-daily, while the FDA-app roved label recommends $10 \mathrm{mcg}$ twice dally after one month based on clinical response Abbreviations. BID, twice per day, $\mathrm{CV}$, cardiovascular diseas

This infographic represents the opinions of the authors. For a full list of 


\section{PLAIN LANGUAGE SUMMARY}

Type 2 diabetes mellitus (T2DM) is a common disorder characterized by insulin resistance and dysfunction of insulin-producing beta cells of the pancreas. People living with T2DM have an increased risk of developing complications, including chronic kidney disease (CKD), which itself is associated with increased mortality. Both the American Diabetes Association and Kidney Disease Improving Global Outcomes organization provide updated pharmacological recommendations for treating T2DM in people with CKD that include the use of sodium-glucose co-transporter-2 inhibitors (SGLT2i) or glucagon-like peptide-1 receptor agonists (GLP1 RAs). GLP-1 RAs are effective and safe treatments for controlling blood sugar levels and reducing body weight, and evidence from large clinical trials also suggests that GLP-1 RAs may be renoprotective. Despite the benefits of GLP-1 RAs, they are not commonly prescribed in people living with T2DM and CKD. Healthcare practitioners need to be aware of the most recent information so that they can make informed decisions when selecting treatment options. The objective of this review is to summarize the main renal outcomes from clinical studies while providing practical guidance on the use of GLP-1 RAs.

Keywords: Chronic kidney disease; Diabetic kidney disease; Glucagon-like peptide-1 receptor agonists; Renal impairment; Type 2 diabetes mellitus

\section{Key Summary Points}

Chronic kidney disease (CKD), characterized by a reduced estimated glomerular filtration rate (eGFR) or the presence of albuminuria and/or other markers of kidney damage for over 3 months, is a common complication of type 2 diabetes mellitus (T2DM) associated with high morbidity and mortality.

Glucagon-like peptide-1 receptor agonists (GLP-1 RAs) are a safe and effective treatment for T2DM that augment insulin secretion and suppress glucagon release via the stimulation of GLP-1 receptors.

Evidence from several large clinical studies indicate that GLP-1 RA therapy is safe for people living with T2DM and compromised renal function and may have renoprotective properties mediated via direct and indirect mechanisms; however, despite evidence of safety and efficacy, and the low risk of hypoglycemia, GLP-1 RA use is uncommon in people living with T2DM and renal impairment.

We review the evidence of GLP-1 RA use in people living with T2DM and CKD and summarize the renal outcomes from key clinical studies. We also provide practical considerations for GLP-1 RA use to provide an added benefit to guide treatment in this high-risk patient population.

The current evidence indicates that GLP-1 RA could add to the arsenal available that addressing persistent gaps in the care of people living with T2DM with or at the risk of developing CKD while reducing the residual renal risk present in those who have already developed CKD. 


\begin{tabular}{|c|c|c|c|c|c|c|}
\hline & & & & \multicolumn{3}{|c|}{$\begin{array}{c}\text { Persistent Albuminuria Categories } \\
\text { Description and Range }\end{array}$} \\
\hline & & & & A1 & $\mathrm{A} 2$ & A3 \\
\hline & & & & $\begin{array}{l}\text { Normal to } \\
\text { mildly } \\
\text { increased }\end{array}$ & $\begin{array}{l}\text { Moderately } \\
\text { increased }\end{array}$ & $\begin{array}{l}\text { Severely } \\
\text { increased }\end{array}$ \\
\hline & & & & $\begin{array}{c}<30 \mathrm{mg} / \mathrm{g} \\
<3 \mathrm{mg} / \mathrm{mmol}\end{array}$ & $\begin{array}{c}30-300 \mathrm{mg} / \mathrm{g} \\
3-30 \mathrm{mg} / \mathrm{mmol}\end{array}$ & $\begin{array}{c}>300 \mathrm{mg} / \mathrm{g} \\
>30 \mathrm{mg} / \mathrm{mmol}\end{array}$ \\
\hline \multirow{6}{*}{ 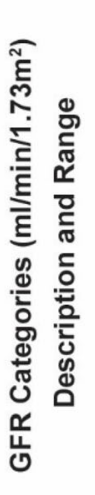 } & G1 & Normal or high & $\geq 90$ & & Monitor & Refer ${ }^{*}$ \\
\hline & G2 & Mildly decreased & $60-89$ & & Monitor & Refer* \\
\hline & G3a & $\begin{array}{l}\text { Mild to moderately } \\
\text { decreased }\end{array}$ & $45-59$ & Monitor & Monitor & Refer \\
\hline & G3b & $\begin{array}{l}\text { Mild to severely } \\
\text { decreased }\end{array}$ & $30-44$ & Monitor & Monitor & Refer \\
\hline & G4 & Severely decreased & $15-29$ & Refer* & Refer* & Refer \\
\hline & G5 & Kidney failure & $<15$ & Refer & Refer & Refer \\
\hline
\end{tabular}

Fig. 1 Classification of CKD based on GFR and albuminuria categories. The risk of CKD progression, morbidity, and mortality are depicted by color (green, low risk; yellow, moderately increased risk; orange, high risk; red, very high risk) and include general decision-making recommendations that are based on expert opinion based on GFR and albuminuria. "Monitor" indicates that eGFR

\section{DIGITAL FEATURES}

This article is published with digital features, including an infographic, to facilitate understanding of the article. To view digital features for this article go to https://doi.org/10.6084/ m9.figshare. 17315696

\section{INTRODUCTION}

\section{Type 2 Diabetes Mellitus and Chronic Kidney Disease}

Chronic kidney disease (CKD) in people living with type 2 diabetes mellitus (T2DM) involves and albuminuria be monitored more frequently. "Refer" indicates referral to a nephrologist; "Refer" indicates that clinicians may wish to discuss treatment or referral with their nephrology service. CKD Chronic kidney disease, GFR glomerular filtration rate. Figure is reproduced with permission (Kidney Disease: Improving Global Outcomes CKD Work Group [133])

the gradual loss of kidney function, characterized by a reduced estimated glomerular filtration rate (eGFR) or the presence of albuminuria for $>3$ months [1]. The Kidney Disease: Improving Global Outcomes (KDIGO) organization provide a classification system for determining CKD risk based on cause, GFR, and albuminuria (Fig. 1) [2]. Of the complications that arise from T2DM, CKD is among the most common, affecting approximately $20-40 \%$ of people [3]. Within 10 years of T2DM diagnosis, $24.9 \%$ of people develop microalbuminuria, $5.3 \%$ develop macroalbuminuria, and $0.8 \%$ develop advanced CKD that includes persistently elevated plasma creatinine or the need for renal replacement therapy [4]. The progression of CKD can lead to end-stage renal disease 
(ESRD), increasing the risk of kidney failure with a need for renal replacement therapy involving dialysis or renal transplant. The predominance of CKD accounts for the increased mortality observed in people living with T2DM [5]. Despite advances in the understanding of disease pathogenesis, and the increased availability of treatment options, the prevalence of ESRD continues to rise in people living with T2DM [6]. With diabetes and CKD projected to be the seventh and fifth leading cause of premature mortality worldwide by 2040 , respectively [7], novel and effective treatment options are critical.

\section{Treatments for CKD in People Living with T2DM}

Findings from systematic reviews and metaanalyses indicate that improved renal outcomes can be achieved through obesity management [8], intensive glycemic control using glucoselowering medications [9], and anti-hypertension drugs [10]. A caveat of using these medications is that many have reduced renal clearance due to declining kidney function or are contraindicated and often require careful dose adjustments [11-13]. Furthermore, several of these therapies have only a modest glucoselowering effect in people with reduced glomerular filtration [14]. For these reasons, limited treatment options exist for this patient population.

Both the American Diabetes Association (ADA), in conjunction with the European Association for the Study of Diabetes (EASD), and KDIGO provide clinical practice guidelines for diabetes management in CKD $[2,3]$. These guidelines recommend a comprehensive strategy be followed to reduce risks of CKD in people living with T2DM and are summarized in Fig. 2. In the Standards of Medical Care in Diabetes2021, the ADA recommend that for people with indications of high risk or established CKD either a sodium-glucose co-transporter-2 inhibitor (SGLT2i) or a glucagon-like peptide-1 receptor agonist (GLP-1 RA) be considered as a treatment option, independently of metformin use [15]. Guidelines provided by KDIGO similarly recommend SGLT2i for people with an eGFR of $\geq 30 \mathrm{ml} / \mathrm{min} / 1.73 \mathrm{~m}^{2}$ due to the vascular and renal benefit, despite its modest effect on glucose control [2]. The current KDIGO guidelines do not recommend SGLT2i for people in more advanced stages of CKD (eGFR $<30 \mathrm{ml} / \mathrm{min} / 1.73 \mathrm{~m}^{2}$ ), as the efficacy for lowering glycated hemoglobin (HbA1c) is blunted. This is indicated in the label information for empagliflozin $[16,17]$ and canagliflozin $[18,19]$, with both of these SGLT2i not recommended for individuals with an eGFR $<30 \mathrm{ml} /$ $\mathrm{min} / 1.73 \mathrm{~m}^{2}$. For dapagliflozin, recently updated prescribing information indicates that initiation of treatment with this SGLT2i is not recommended in individuals with an eGFR < $25 \mathrm{ml} / \mathrm{min} / 1.73 \mathrm{~m}^{2}[20,21]$. In people with T2DM and CKD, who have not achieved individualized glycemic targets despite use of metformin and SGLT2i, or are unable to use those medications due to contraindications, longacting GLP-1 RAs are recommended [2]. The use of GLP-1 RAs in this population is not only due to the limited use of SLGT2i in more severe stages but also because the glycemic lowering efficacy of SLGT2i is reduced in individuals with moderate renal impairment and likely absent in those with severe renal impairment. These antihyperglycemic therapies have shown promise in directly improving renal outcomes and reducing CKD progression independently of glycemic control $[2,15]$. The use of GLP-1 RAs is also associated with a low risk for hypoglycemia, which is a limiting factor for many other diabetes medications in people with renal impairment.

\section{Treatment with GLP-1 RA in People Living with T2DM and CKD}

The GLP-1 RA class of medications are incretinmimetics that have been available from 2005, of which exenatide was the first to receive approval from the U.S. Food and Drug Administration (FDA). Since then, additional GLP-1 RAs have gained regulatory approval in both the USA and Europe. These medications have been demonstrated to be safe and effective in controlling glycemia through HbA1c reduction 


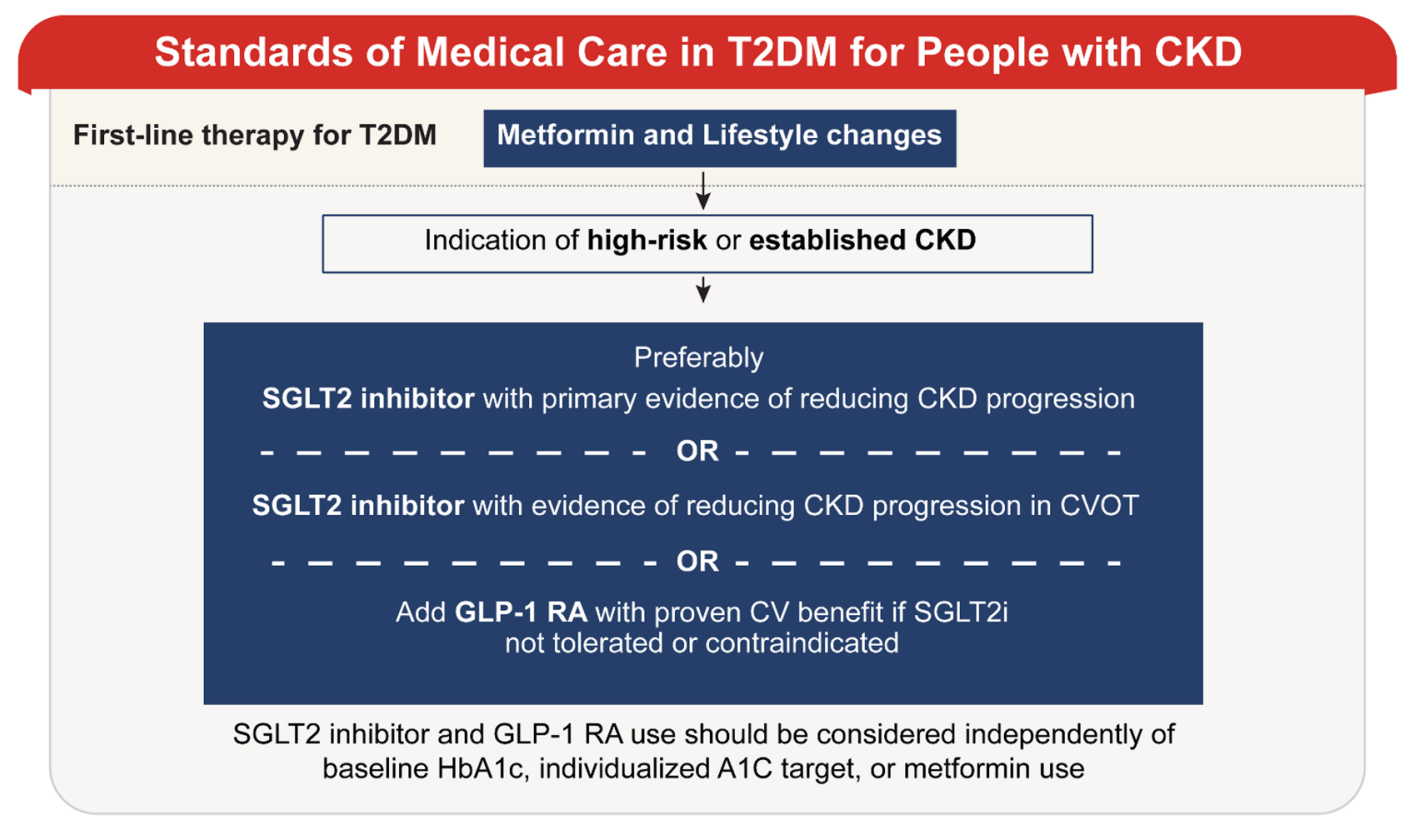

\section{Clinical Practice Guidance for People with T2DM and CKD}

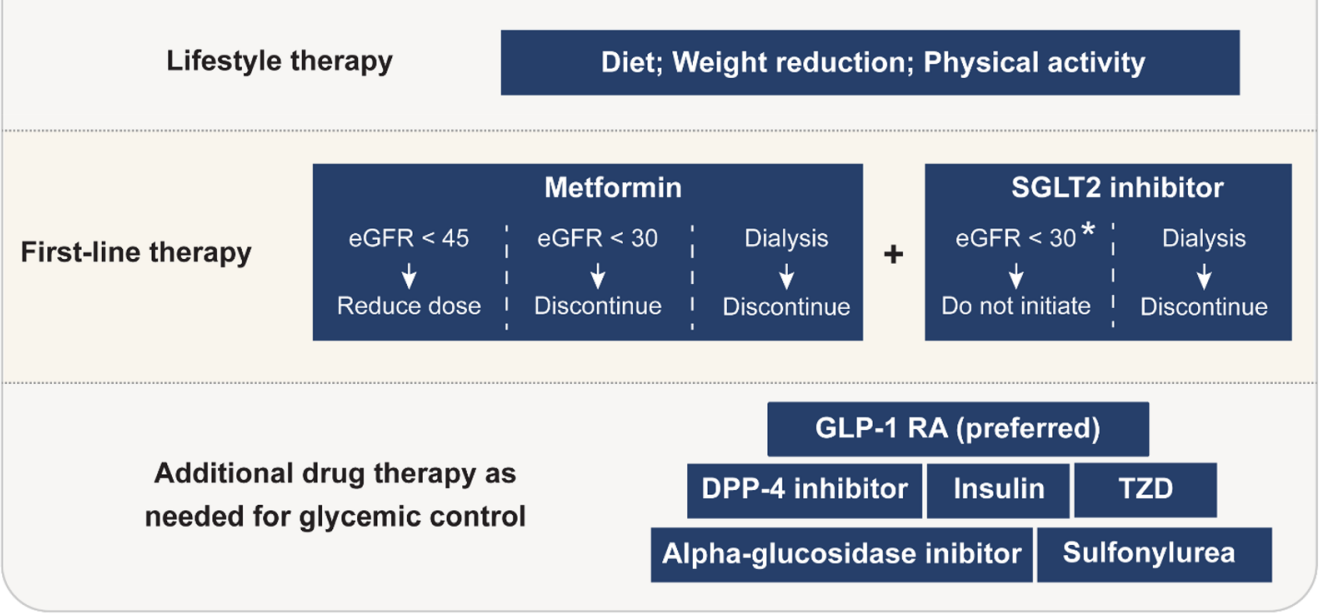

Fig. 2 Summary of ADA and KDIGO guidelines of use for glucose-lowering medication in people living with T2DM and CKD. Upper panel: ADA guidelines were abbreviated for specific treatment for people living with T2DM and CKD. Proven CVD benefit means it has label indication of reducing CVD events. For more context regarding glucose lowering medication in this population, refer to the Standards of Medical Care in Diabetes-2021 [15]. Lower panel: KDIGO recommend guidelines of glycemic management for people living with T2DM and CKD begin with lifestyle therapy followed by first-line pharmacological therapy with metformin and SGLT2i. For people contraindicated for SGLT2i, GLP-1 RAs are recommended. Additional drug therapy is guided by patient preferences, comorbidities, eGFR, and cost, and includes people with eGFR $<30 \mathrm{ml} / \mathrm{min}$ per $1.73 \mathrm{~m}^{2}$ or those treated with dialysis [2]. *: Dapagliflozin; it is not recommended to initiate treatment with dapagliflozin in patients with GFR $<25 \mathrm{ml} / \mathrm{min} / 1.73 \mathrm{~m}^{2}[20,21]$. ADA American Diabetes Association, $C V$ cardiovascular, $C V O T$ cardiovascular outcome trial, DPP-4 dipeptidyl peptidase-4, eGFR estimated GFR, GLP-1 RA glucagon-like peptide-1 receptor antagonist, $H b A c 1$ glycated hemoglobin, $S G L T 2 i$ sodium-glucose cotransporter-2 inhibitor, T2DM type 2 diabetes mellitus, TZD thiazolidinediones. The figure was created by Lilly using the data from the American Diabetes Association [15] and Kidney Disease: Improving Global Outcomes Diabetes Work Group [2]. Permission is not required as only data were used 
[22]. The glucose-lowering effect is due to GLP-1 RA binding to the glucagon-like peptide-1 (GLP1) receptor in the pancreas where insulin secretion is promoted while glucagon secretion is suppressed. Additional benefits include improved metabolic control and weight loss by acting on the gut, where they slow gastric emptying, and the central nervous system, where they suppress appetite [23, 24]. Target tissues for GLP-1 are highlighted in Fig. 3 and include the heart and kidney [25]. The GLP-1 RAs have been shown to improve cardiovascular outcomes, with liraglutide, semaglutide, albiglutide, and dulaglutide demonstrating a reduction of major cardiovascular events in people with established cardiovascular disease [26-29]. Dulaglutide has also demonstrated reduced cardiovascular outcomes in people without established cardiovascular disease. These agents act on the kidneys, with clinical evidence suggesting they promote renal protection [30-33]. Direct renal benefits include decreased glomerular atherosclerosis, inhibition of the renin-angiotensin system, stimulation of proximal tubule natriuresis, and reduced fibrosis, inflammation, and oxidative stress, while they indirectly reduce renal risk factors by reducing hypertension, decreasing weight, and improving glycemic control. The potential direct and indirect benefits mediated by GLP-1 RA are summarized in Fig. 4. For a more detailed overview on the potential mechanisms by which GLP-1 RA may exert these effects on the kidney, we refer readers to recent review articles [34, 35]. Importantly unlike many other glucose-lowering medications, including metformin, sulfonylureas, and alpha-glucosidase inhibitors [36], GLP-1 RAs do not have a relative contraindication in people with renal impairment.

Despite demonstrating benefits beyond blood glucose control, GLP-1 RAs are not yet commonly prescribed in people living with T2DM and CKD [37]. The purpose of this review is to summarize the clinical evidence regarding the effect of GLP-1 RAs on renal outcomes in people living with T2DM and CKD and to provide an overview of the practical aspects of use of these compounds that include specific considerations for this high-risk patient population.

\section{EVIDENCE FROM CLINICAL TRIALS}

\section{General Overview of Cardiovascular Outcome Trials}

Currently, clinical trials that report kidney outcomes as the primary endpoint of GLP-1 RA therapy are lacking. The most reliable evidence for positive renal outcomes from GLP-1 RA use comes from cardiovascular outcomes trials (CVOTs); however, these studies were not designed or powered for this specific purpose. These trials were conducted in response to guidelines mandated by the U.S. FDA in 2008 which suggested that sponsors evaluate new T2D therapies for cardiovascular risk [38]. Since 2015, seven CVOTs have been completed that assess the cardiovascular safety and efficacy of GLP-1 RAs, including ELIXA (lixisenatide) [39], LEADER (liraglutide) [26], SUSTAIN-6 (semaglutide) [27], EXSCEL (exenatide) [40], HARMONY (albiglutide) [28], REWIND (dulaglutide) [29], and PIONEER-6 (oral semaglutide) [41]. Although only the CVOTs investigating liraglutide, semaglutide, albiglutide, and dulaglutide independently demonstrated a reduction in the three-component major adverse cardiovascular events (MACE-3) score (consisting of cardiovascular death, myocardial infarction, and stroke), a metaanalysis combining results demonstrated that GLP-1 RA treatment decreased MACE-3 by $12 \%$ (hazard ratio [HR] 0.88, 95\% confidence interval [CI] 0.82-0.94), indicating improved cardiovascular outcomes in people living with T2DM and established cardiovascular disease [42].

\section{Evidence Regarding Renal Outcomes With GLP-1 RA Use}

Although no clinical trials have been published reporting kidney outcomes as the primary endpoint of GLP-1 RA therapy, several CVOTs indicate that GLP-1 RAs may promote renal benefits and delay CKD progression through secondary or exploratory endpoints that include decreased onset of macroalbuminuria and reduced eGFR decline [43-45]. Secondary endpoints of the CVOTs LEADER [46], 


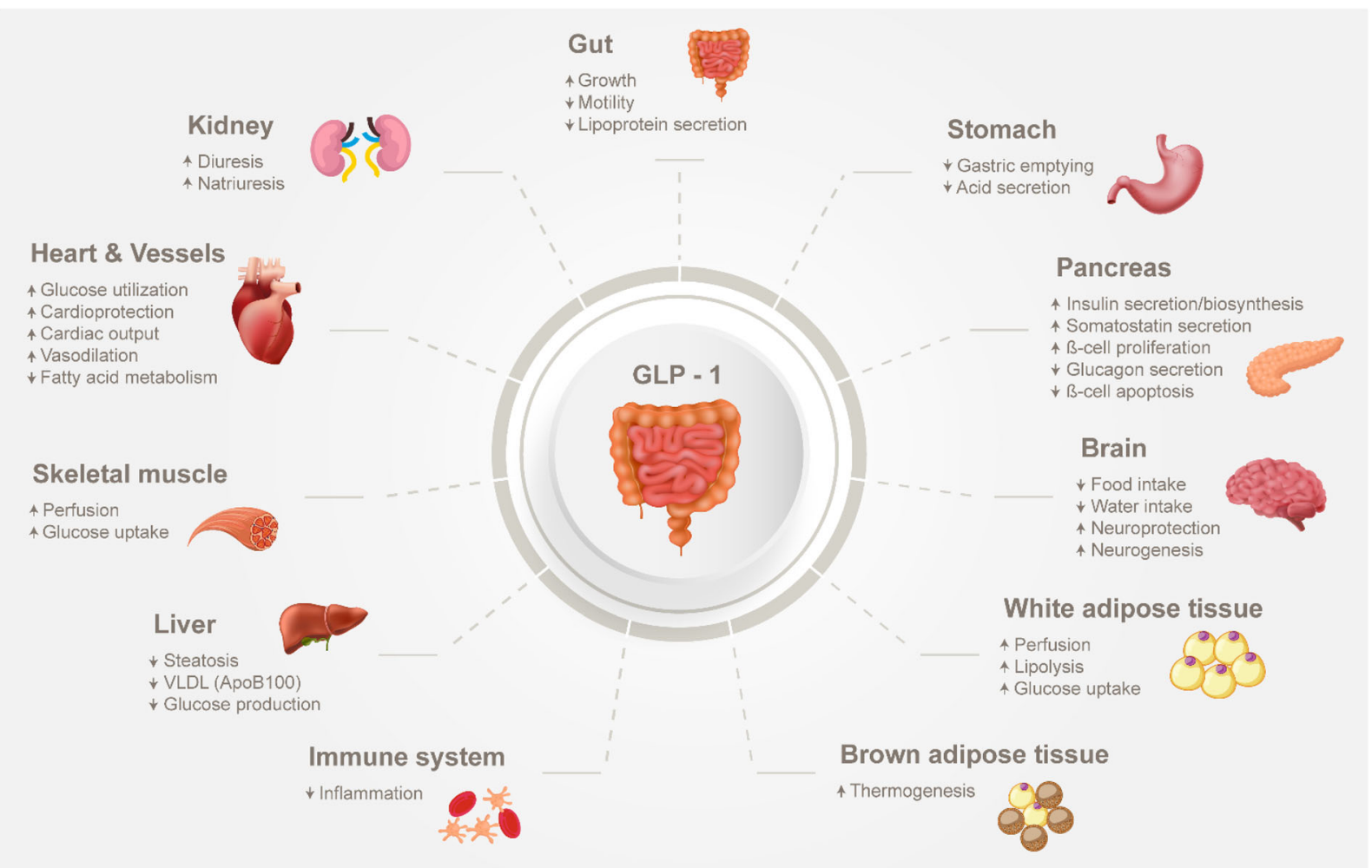

Fig. 3 Physiological targets of GLP-1. GLP-1 exhibits pleotropic attributes that affect various tissues and organs, including the pancreas, stomach, brain, liver, adipose, heart, and kidney. GLP-1 Glucagon-like peptide-1, VLDL

SUSTAIN-6 [27], and REWIND [32] showed reduced progression of nephropathy with no increase in acute kidney injury. Although the reported outcomes differ from trial to trial, there are strong indications that give confidence to the net benefit of GLP-1 RAs. Indeed, in a meta-analysis of CVOTs examining renal outcomes of GLP-1 RAs, the authors found that GLP-1 RAs clearly reduced the risk of worsening of kidney function when assessed using a broad composite renal outcome [42]. A summary of these large clinical studies is presented below and summarized in Table 1.

\section{The ELIXA Trial (Once-Daily Lixisenatide)}

The Evaluation of Lixisenatide in Acute Coronary Syndrome (ELIXA) CVOT trial assessed the effects of lixisenatide on cardiovascular outcomes in people living with T2DM with a previous acute coronary event [47]. In a very-low-density lipoprotein. The figure was created by Lilly using the data from Muskiet et al. [25]; permission is not required as only data were used

following exploratory analysis, renal outcomes were investigated that consisted of percentage change in urine albumin-to-creatinine ratio (UACR) and eGFR according to prespecified albuminuria status at baseline using a mixedeffect model with repeated measures. Lixisenatide was associated with a reduced risk of newonset macroalbuminuria $(>300 \mathrm{mg} / \mathrm{g})$ and reduced progression of UACR in people with macroalbuminuria when compared with placebo; however, no significant differences in eGFR decline were identified in any of the treatment groups [44].

\section{The LIRA-RENAL Trial (Once-Daily Liraglutide)}

The Efficacy and Safety of Liraglutide Versus Placebo as Add-on to Glucose-Lowering Therapy in Patients With Type 2 Diabetes and Moderate Renal Impairment (LIRA-RENAL) trial 


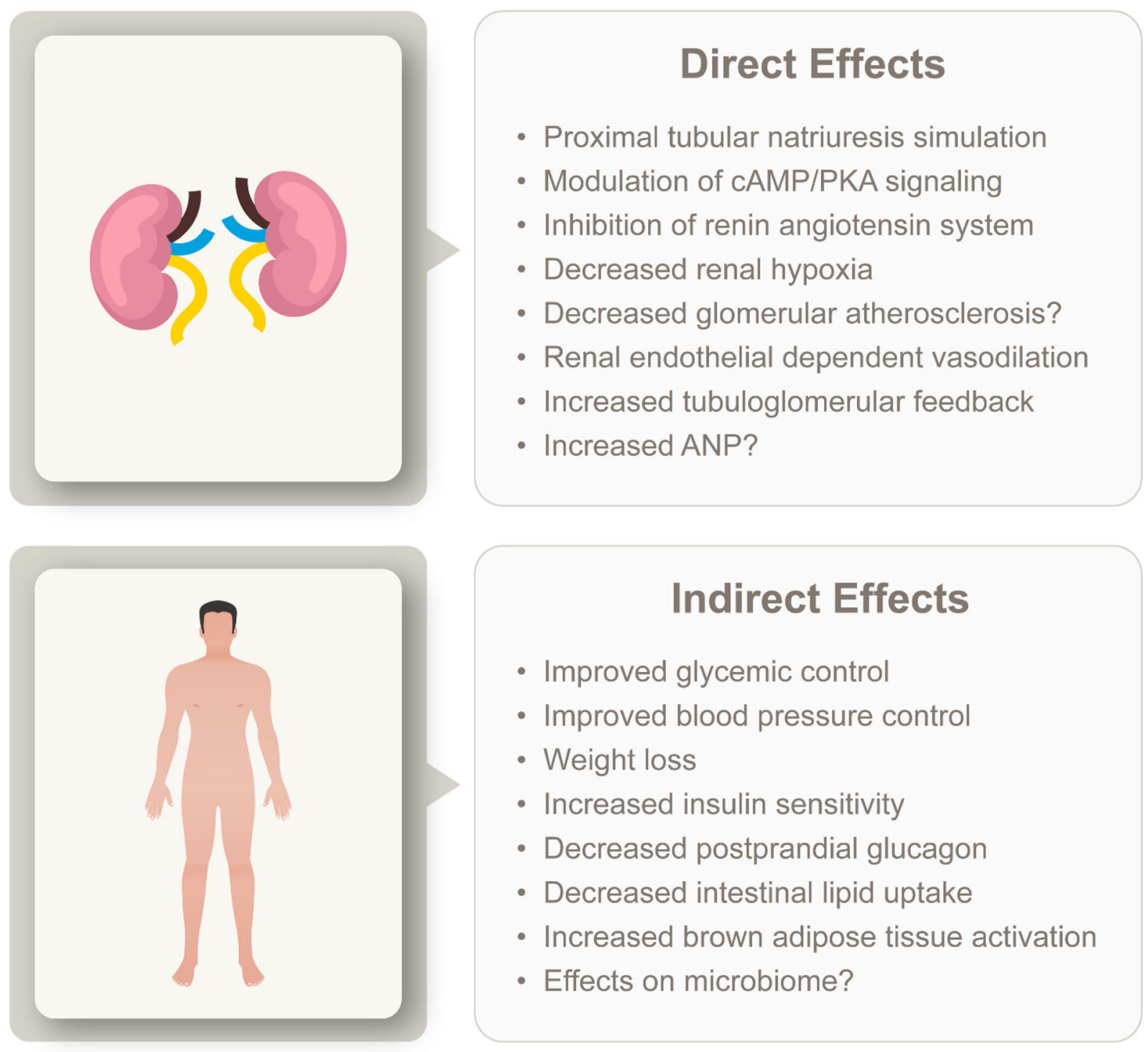

Fig. 4 Potential direct and indirect renoprotective effects of GLP-1 RAs. $c A M P / P K A$ Cyclic adenosine monophosphate/protein kinase A, $A N P$ atrial natriuretic peptide.

investigated the efficacy and safety of liraglutide as an add-on to existing glucose-lowering medications in people with inadequately controlled T2DM and moderate renal impairment (stage 3 CKD, eGFR $30-59 \mathrm{ml} / \mathrm{min} / 1.73 \mathrm{~m}^{2}$ ) [48]. After 26 weeks, along with a greater change in $\mathrm{HbA1c}$ from baseline, no changes in renal function were observed with liraglutide when compared to placebo.
The figure was created by Lilly using the data from Greco et al. (see Table 1) [35]. Permission is not required as only data were used

The LEADER Trial (Once-Daily Liraglutide)

The LEADER trial primarily assessed the cardiovascular safety of once-daily liraglutide compared to placebo [26]. The trial included 9340 participants ( $\geq 50$ years; HbA1c $\geq 7.0 \%$ ), the majority with established cardiovascular disease (81\%). Renal outcomes were explored in a prespecified secondary analysis [30]. The secondary renal outcome was a composite of the following components: new-onset persistent 


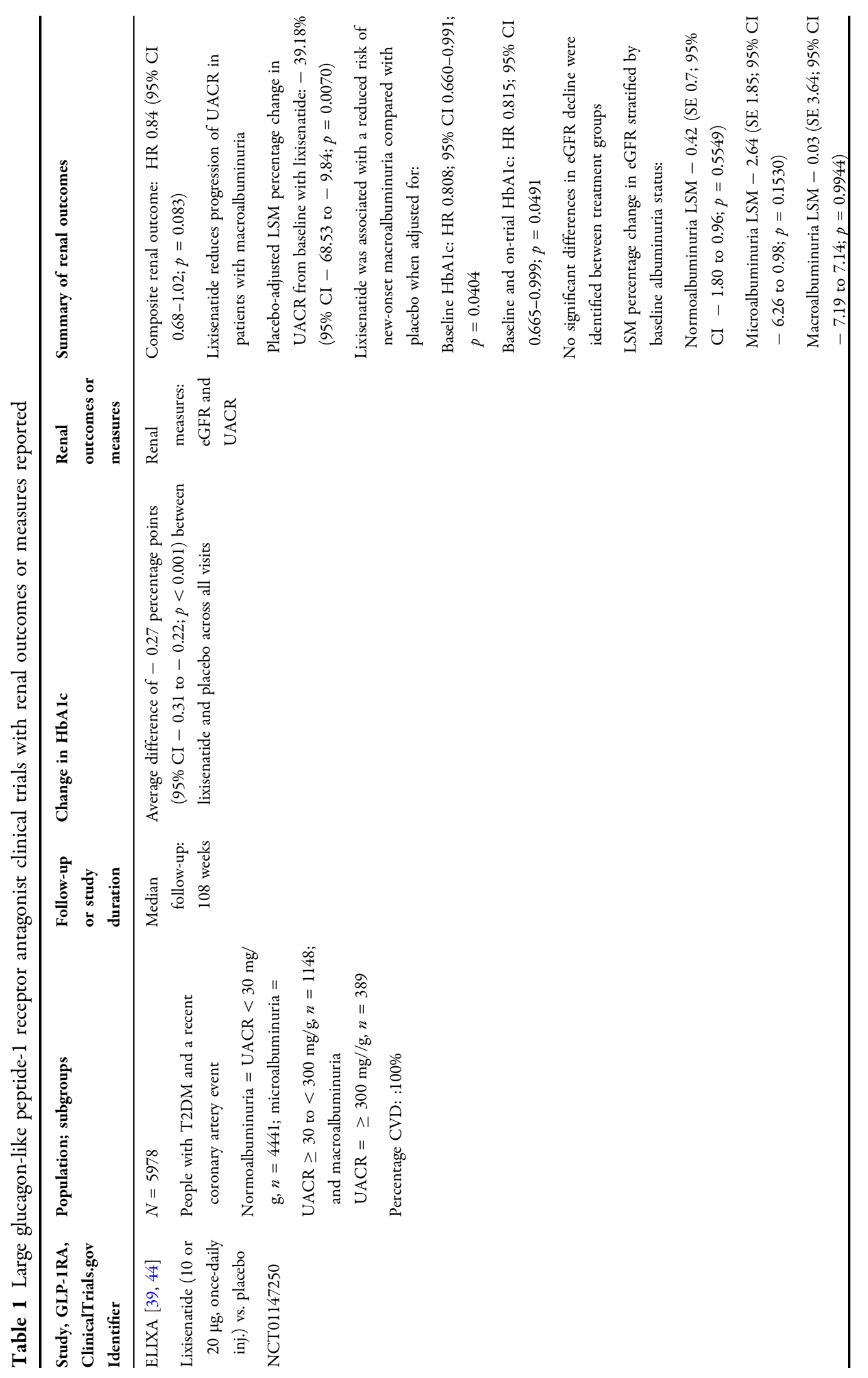




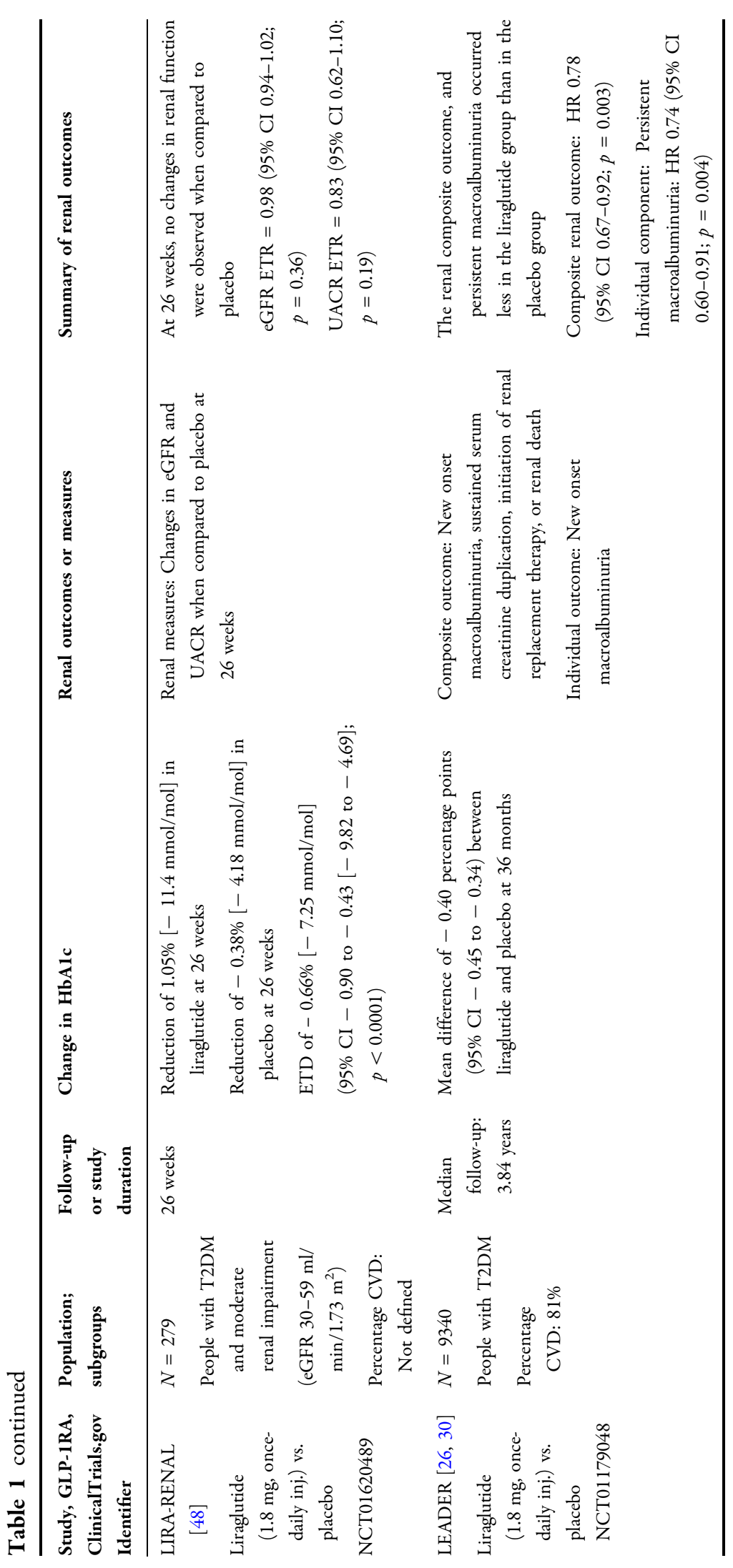




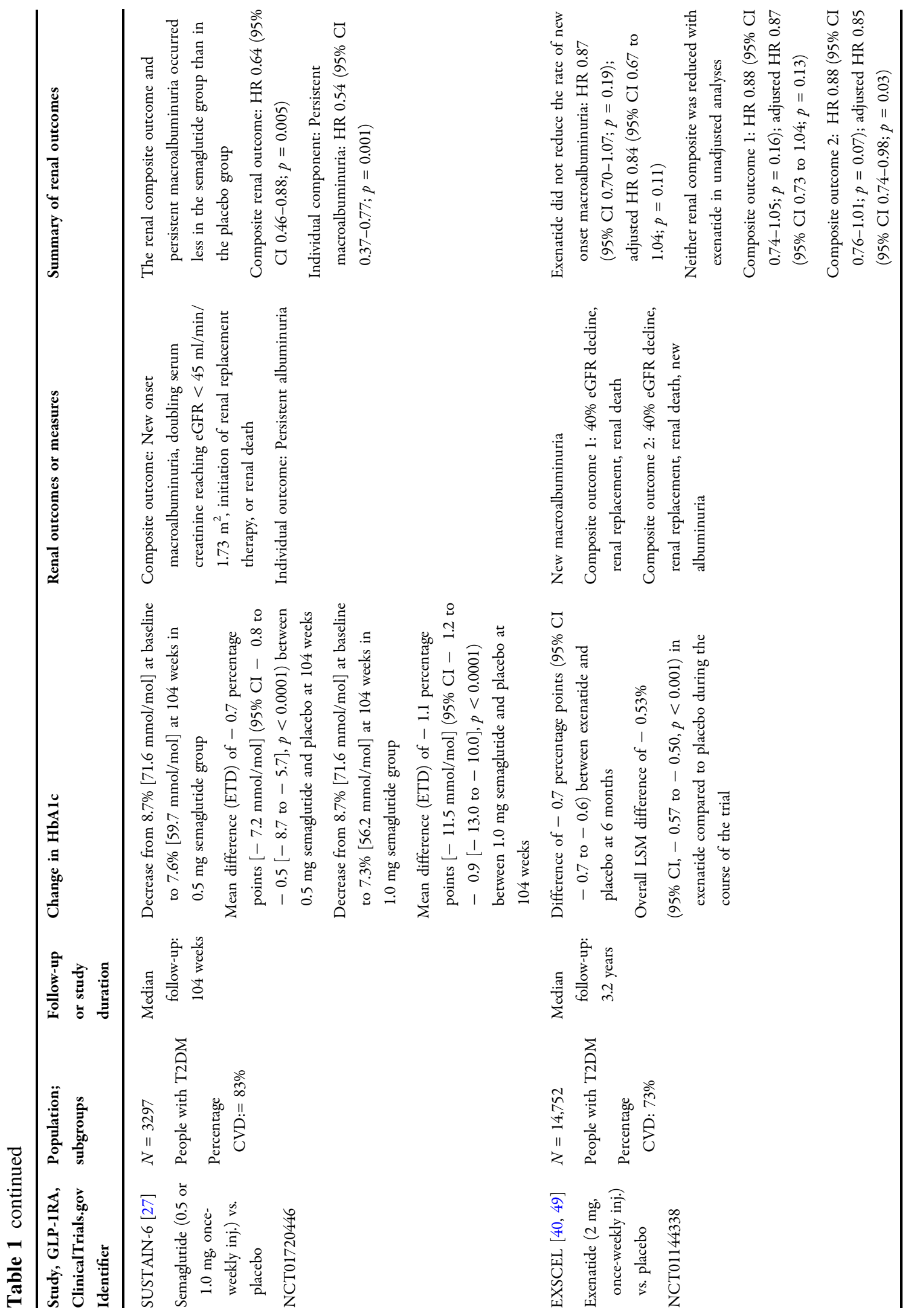




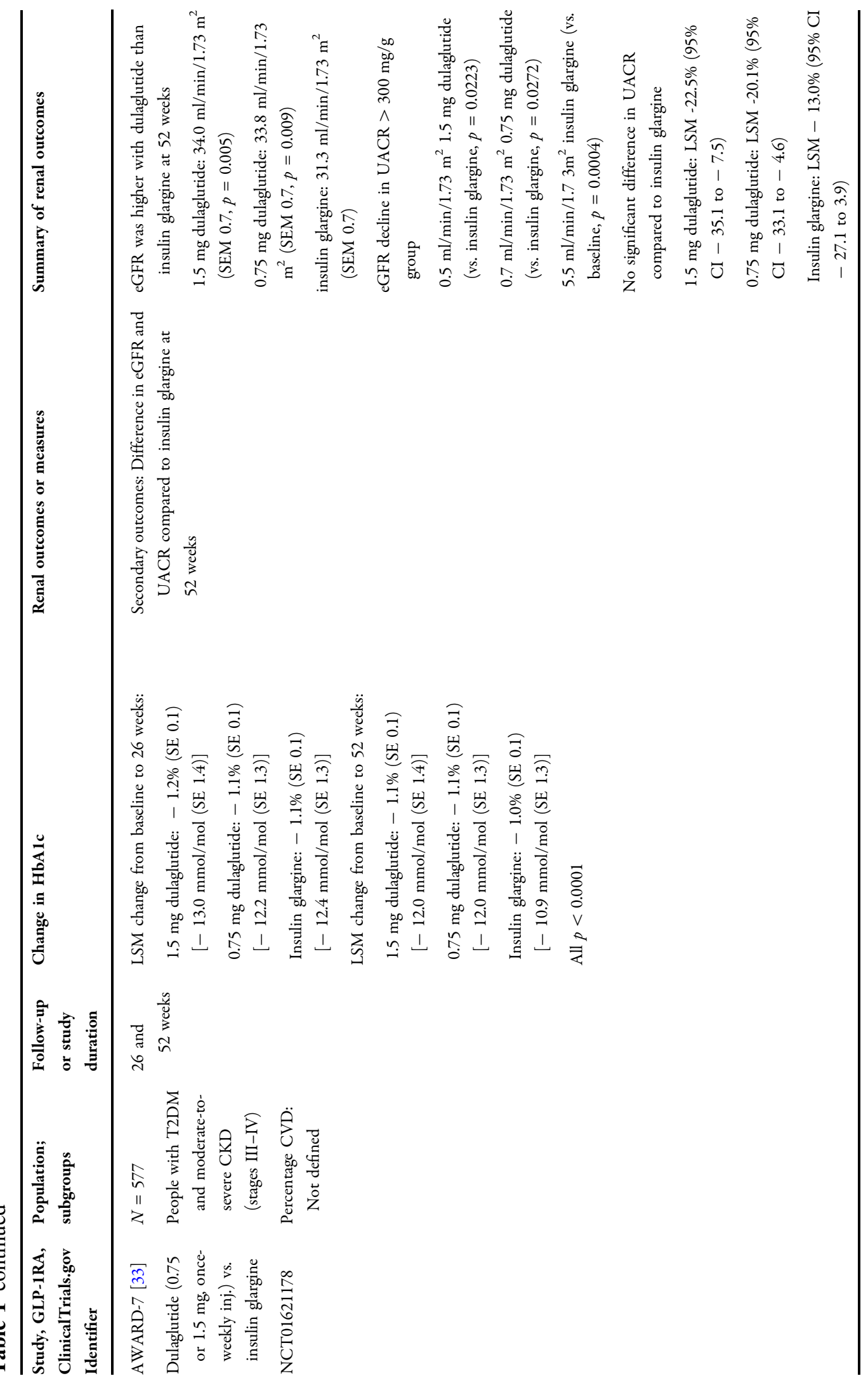




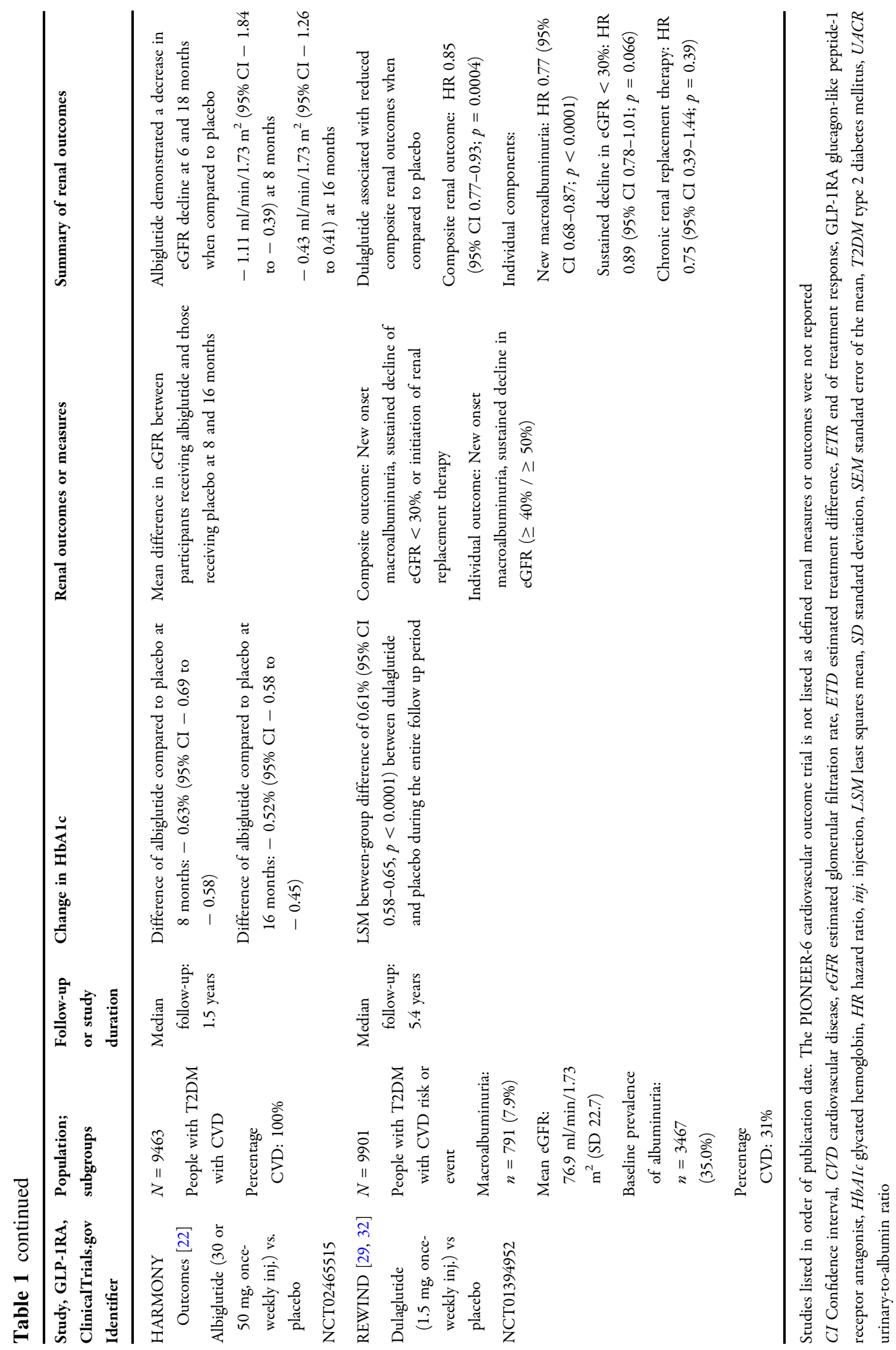


macroalbuminuria, persistent doubling of the serum creatinine level, ESRD, or death due to renal disease. The composite renal outcome was observed less frequently in participants using liraglutide than placebo (HR 0.78, 95\% CI $0.67-0.92 ; p=0.003)$. Of the individual components, only new-onset persistent macroalbuminuria was observed less frequently in people treated with liraglutide (HR 0.74, 95\% CI $0.60-0.91 ; p=0.004)[30]$.

\section{The SUSTAIN-6 Trial (Once-Weekly Semaglutide)}

The Trial to Evaluate Cardiovascular and Other Long-term Outcomes with Semaglutide in Subjects with Type 2 Diabetes (SUSTAIN-6) consisted of 3297 people living with T2DM, 83\% with established cardiovascular disease, receiving once-weekly semaglutide $(0.5$ and $1.0 \mathrm{mg})$ or placebo. New or worsening nephropathy, defined as persistent macroalbuminuria, persistent doubling of the serum creatinine level, and a creatinine clearance of $<45 \mathrm{ml} / \mathrm{min} / 1.73 \mathrm{~m}^{2}$, or the need for continuous renal-replacement therapy, was observed less in participants treated with semaglutide $(3.8 \%)$ than placebo (6.1\%) [27].

A recent post-hoc analysis of the SUSTAIN trials (SUSTAIN 1-5 and SUSTAIN 7) assessed the effects of semaglutide $(0.5$ and $1.0 \mathrm{mg})$ versus comparators (active treatments or placebo) on kidney function (eGFR), albuminuria status (UACR), and adverse kidney events in 8416 people living with T2DM [31]. Semaglutide was associated with initial reductions in eGFR that plateaued and marked reductions in UACR when compared to active comparators.

\section{The EXSCEL Trial (Once-Weekly Exenatide)}

The Exenatide Study of Cardiovascular Event Lowering (EXSCEL) was a multinational, placebo-controlled, randomized CVOT designed to assess the impact of once-weekly exenatide compared to placebo when added to usual care in people living with T2DM and risk of cardiovascular disease. In a recent post-hoc analysis, renal outcomes were measured, including new macroalbuminuria and two composite outcomes consisting of $40 \%$ decline in eGFR, renal replacement, and renal death, with or without new macroalbuminuria. Neither renal composite was reduced with exenatide in unadjusted analyses; however, the second renal composite containing macroalbuminuria was reduced after adjustment when compared to placebo (HR 0.85, 95\% CI 0.74-0.98) [49].

\section{The AWARD-7 Trial (Once-Weekly Dulaglutide)}

The Assessment of Weekly Administration of LY2189265 in Diabetes-7 (AWARD-7) study assessed the glycemic efficacy and overall safety of once-weekly 1.5 and $0.75 \mathrm{mg}$ dulaglutide compared to insulin glargine in 577 people living with T2DM and moderate-to-severe CKD (eGFR $<60 \mathrm{ml} / \mathrm{min} / 1.73 \mathrm{~m}^{2}$ ) [33]. At 52 weeks, in addition to producing glycemic control similar to that achieved with insulin glargine but with lower rates of symptomatic hypoglycemia, dulaglutide was associated with a reduced decline in eGFR. However, the reduction of UACR with dulaglutide was not significantly different from that of insulin glargine. This study was the first to demonstrate that in people with moderate-to-severe CKD, GLP-1 RA treatment may slow eGFR decline.

\section{The Harmony Outcomes Trial (Once-Weekly Albiglutide)}

The Harmony Outcomes study evaluated the cardiovascular safety of once-weekly treatment with 30 or $50 \mathrm{mg}$ albiglutide in 9463 people living with T2DM and cardiovascular disease compared with placebo. Renal outcomes were not reported, however, eGFR was measured [28]. The mean difference in eGFR between participants receiving albiglutide and those receiving placebo was -1.11 and $-0.43 \mathrm{ml} / \mathrm{min} / 1.73$ $\mathrm{m}^{2}$ at 8 and 16 months, respectively. In August 2017, GlaxoSmithKline announced that it would discontinue albiglutide due to limited prescribing of the drug and not because of safety concerns.

The REWIND Trial (Once-Weekly Dulaglutide) The Researching Cardiovascular Events with a Weekly Incretin in Diabetes (REWIND) trial consisted of 9901 participants, of whom 31.5\% had 
previous cardiovascular disease, with a median follow-up of 5.4 years [29]. Predefined secondary outcomes showed that $1.5 \mathrm{mg}$ once-weekly dulaglutide was associated with reduced composite renal outcomes, defined as the first occurrence of new macroalbuminuria, sustained decline in eGFR of $\geq 30 \%$, or chronic renal replacement therapy [32]. A post-hoc analysis evaluated the effect of dulaglutide and placebo on renal outcomes related to kidney function, defined as the composite endpoint of sustained eGFR decline $\geq 40 \%$, ESRD, or all-cause death [50]. The incidence rate of the composite endpoint was determined to be significantly lower in participants treated with dulaglutide compared with placebo (HR 0.83, 95\% CI $0.75-0.92, p<0.001)$.

The PIONEER-6 Trial (once-daily semaglutide) The Peptide Innovation for Early Diabetes Treatment-6 (PIONEER-6) trial assessed CV safety of oral semaglutide in 3,183 participants of whom $856 \mathrm{had}$ an eGFR $<60 \mathrm{ml} / \mathrm{min} / 1.73$ $\mathrm{m}^{2}$ and 1051 had microalbuminuria or proteinuria [41]. Renal or microvascular composite endpoints were not assessed; however, a CVOT of oral semaglutide is planned with renal outcomes as secondary endpoints (A Heart Disease Study of Semaglutide in Patients With Type 2 Diabetes [SOUL]) [51].

Future studies are needed dedicated to understanding the primary kidney outcomes of GLP-1 RA use and to confirm the renoprotective benefits of this drug class.

The FLOW (A Research Study to See How Semaglutide Works Compared to Placebo in People With Type 2 Diabetes and Chronic Kidney Disease) trial will be the first study designed to specifically examine the effects of a GLP-1 RA on primary kidney outcomes.[52]. The trial is ongoing with results to be expected between 2024 and 2025. Challenges for conducting such trials include their expense, due to being both large and long-term, a high regulatory bar, and difficulty in enrolling enough participants in this particular population $[53,54]$.

\section{Other Clinical Evidence for GLP-1 RAs}

In addition to the larger randomized controlled trials described above, evidence for GLP-1 RA use in people living with CKD comes from nonrandomized clinical studies and clinical trials with small sample sizes. In a prospective study published in 2017, the Hiramatsu group reported that in Japanese people living with T2DM and mild renal impairment (eGFR 30-60 ml/ $\min / 1.73 \mathrm{~m}^{2}$ ) liraglutide was associated with decreased albuminuria (baseline $\beta 2$-microglobulin $\quad 2.52 \pm 0.7 \mathrm{mg} / \mathrm{dL}, \quad 24$-month $\beta 2$-microglobulin $2.13 \pm 0.9 \mathrm{mg} / \mathrm{dL} ; p<0.05)$ and an increased eGFR after 24 months (baseline eGFR $51.2 \pm 8.1 \mathrm{~mL} / \mathrm{min} / 1.73 \mathrm{~m}^{2}$, 24-month eGFR $\left.60.5 \pm 13.8 \mathrm{~mL} / \mathrm{min} / 1.73 \mathrm{~m}^{2} ; p<0.05\right)$ [55]. Two other studies with low participant number also reported that liraglutide positively impacted renal function while demonstrating reductions in HbA1c and body weight $[56,57]$. Inamura et al. reported that 12-month administration of liraglutide decreased both the rate of eGFR decline $(6.6 \pm 1.5$ to $0.3 \pm 1.9 \mathrm{ml} / \mathrm{min} /$ $1.73 \mathrm{~m}^{2} /$ year; $\left.p=0.003\right)$ and proteinuria $(2.53 \pm 0.48$ to $1.47 \pm 0.28 \mathrm{~g} / \mathrm{g}$ creatinine; $p=0.002$ ) [57] while von Scholten et al. showed, in a randomized, placebo-controlled, crossover trial, that liraglutide reduced the urinary albumin excretion rate $(32 \%$ reduction, $95 \%$ CI $7-50 ; p=0.017)$ and eGFR $(-5 \mathrm{~mL} /$ $\mathrm{min} / 1.73 \mathrm{~m}^{2}, 95 \% \mathrm{CI}-11$ to $\left.2 ; p=0.15\right)$ over a 12 -week period, a reduction that may be attributed to decreased 24-h systolic blood pressure [56]. As hyperglycemia can affect filtration rates [58], a limitation of these studies is that the renal findings reported were not determined to be independent of glucose lowering.

\section{Evidence from Real-world Studies}

Other supporting evidence for the use of GLP-1 RAs in this patient population comes from realworld evidence studies. A retrospective study examining the effects of initiating GLP-1 RA therapy on eGFR in people living with T2DM with renal impairment showed that after 1 year from initiating GLP-1 RA therapy, people living 
with stage 4 CKD (eGFR of $<30$ and $\geq 15 \mathrm{ml}$ / $\min / 1.73 \mathrm{~m}^{2}$ ) or stage 5 CKD (eGFR of $<15 \mathrm{ml}$ / $\min / 1.73 \mathrm{~m}^{2}$ ) had a significantly smaller decline in eGFR compared to those using other glucoselowering agents [37]. In a retrospective study evaluating the effectiveness of dulaglutide in routine clinical practice that included patient subgroups underrepresented in clinical trials, including elderly people, non-obese individuals, and those with CKD, a significant and consistent improvement in HbA1c with declining body weight was observed [59]. Specifically, of the participants in the study who had CKD, dulaglutide achieved significant reductions in HbA1c $(-0.9 \%)$ and body weight $(-4.6 \mathrm{~kg})$, consistent with results of the AWARD-7 trial [33].

\section{Evidence from Kidney Transplant and People Living with Dialysis}

Currently, no prospective clinical trials have yet assessed the effectiveness, safety, and tolerability of GLP-1 RAs in people living with T2DM and stage 5 CKD in dialysis programs or in those who have undergone kidney transplant [60]. Several retrospective studies indicate no significant changes in renal function and suggest that GLP-1 RAs have no effect on transplant outcomes $[61,62]$. In a retrospective review of kidney transplant recipients with pre- or posttransplant diabetes who initiated a GLP-1 RA therapy for at least 12 months, recipients showed a significant reduction in the total daily insulin dose, a reduction in the risk of hypoglycemia, and the maintenance of kidney function with no acute rejection, indicating that GLP-1 RA may be a relatively safe and effective treatment for kidney transplant recipients with T2DM [62]. Another retrospective study involving people living with T2DM treated with GLP-1 RAs who had received kidney transplants showed decreased $\mathrm{HbA1c}$ and weight but no change in renal function after a mean follow-up period of 12 months [61]. In a separate smaller study $(n=7)$, improvements in renal function were observed along with HbA1c and weight reductions after a mean follow-up period of $19.4 \pm 7.6$ months [63]. Furthermore, a retrospective chart review of people living with T2DM and a solid organ transplant, of which the majority had a kidney transplant (81\%), dulaglutide treatment resulted in a sustained reduction in weight, body mass index (BMI), and insulin use over a 24-month period with no increase in graft failure, cardiovascular morbidity, or all-cause mortality [64]. The lack of major concerns indicates that GLP-1 RAs may be a viable treatment for people living with T2DM post-kidney transplant, although more studies are needed to determine whether these medicines improve patient survival.

Limited studies have been performed examining GLP-1 RA use in individuals with ESRD (eGFR $<15 \mathrm{ml} / \mathrm{min} / 1.73 \mathrm{~m}^{2}$ ), and the recommendations of their use in this population differ depending on GLP-1 RA as well as the prescribing information set by the regulator (summarized in Fig. 5). Clinical pharmacology studies have demonstrated that renal impairment, including ESRD requiring dialysis, does not impact the pharmacokinetics of semaglutide or dulaglutide as indicated in their label information $[65,66]$. The pharmacokinetic characteristics of GLP-1 RAs together with the potential benefit of these drugs in reducing HbA1c without risk of hypoglycemia, warrant further research on the possible use of GLP-1 RA in people with advanced CKD and those on dialysis.

\section{PRACTICAL USE OF GLP-1 RAS IN PEOPLE LIVING WITH CKD}

In this section we provide general recommendations for GLP-1 RA use in people with CKD. The information for GLP-1 RA use for patients without CKD will also be included to enhance the context.

\section{Current Treatment Guidelines for People Living with CKD}

By nature, T2DM is a heterogenous and progressive disease for which a wide variety of treatment options exist and where treatment paradigms continue to evolve. Several 


\begin{tabular}{c|c|c|c|c|c|} 
CKD Stage & 5 & 4 & 3 & 2 & 1 \\
\hline $\begin{array}{c}\text { eGFR }\left(\mathrm{mL} / \mathrm{min} / 1.73 \mathrm{~m}^{2}\right) / \\
\text { Creatinine clearance }(\mathrm{mL} / \mathrm{min})\end{array}$ & $<15^{*}$ & $15-29$ & $30-59$ & $60-89$ & $\geq 90$
\end{tabular}

US Prescribing Information ${ }^{a}$

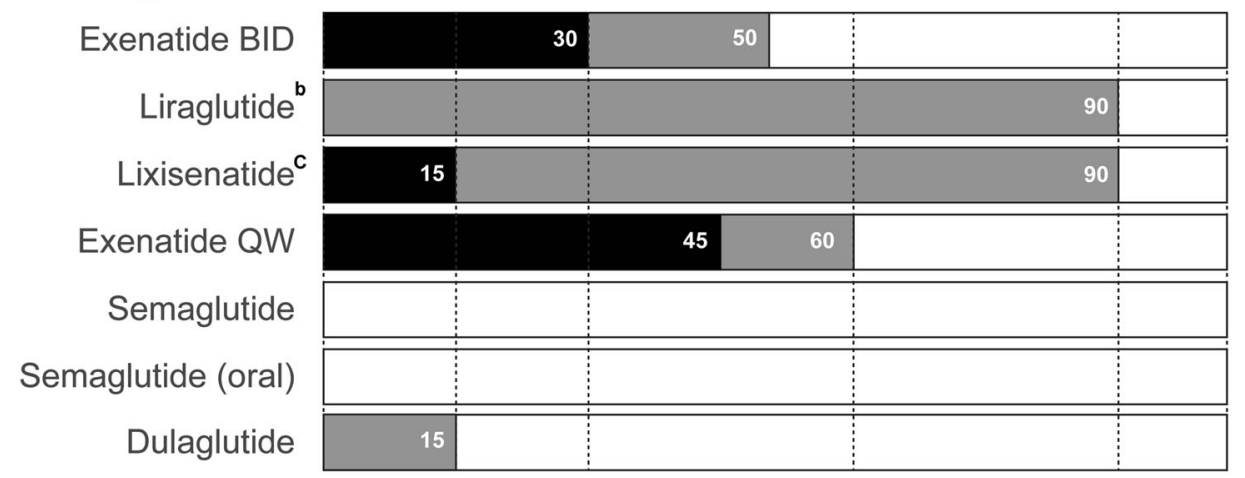

EMA Summary of Product Characteristics

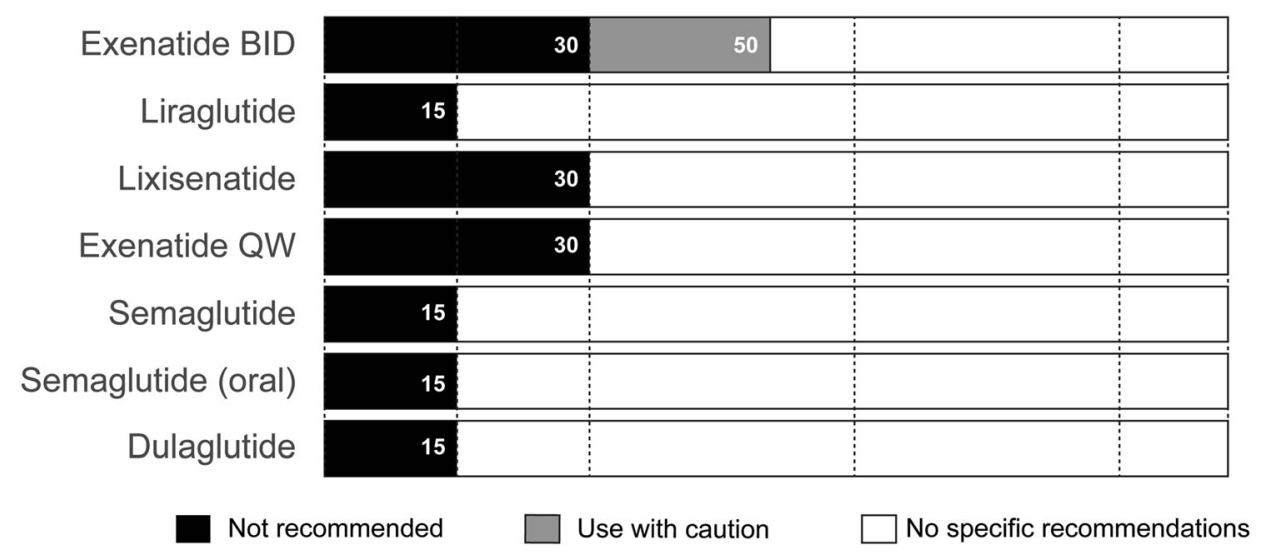

Fig. 5 Information on the use of GLP-1 RA in people with T2DM and CKD based on USPI and the European Union SmPC. The FDA-approved prescribing information and EMA-approved SmPC summarizing GLP-1RA use in populations with renal impairment. Recommendations are depicted by color (white, no specific recommendation; gray, use with caution; black, not recommended). *: For the purposes of graphically summarizing the information on GLP-1 RA use in people with renal impairment, end-stage renal disease, as described in the SmPC and USPI, is defined as eGFR $<15 / \mathrm{mL} / \mathrm{min} / 1.73^{2}$ when

international organizations have provided clinical practice guidelines to aid physicians in optimizing therapy for people living with CKD.

The general guidelines for management of T2DM that are provided by the ADA can aid physicians in navigating the overall treatment landscape. Pharmacologic intervention is specific eGFR values are not provided in the label information. ${ }^{\text {a}}$ Information is based on FDA-approved label unless superseded by the most recent USPI as of 20 May 2021. ${ }^{\mathrm{b}}$ Limited experience exists for liraglutide use in people with end-stage renal disease. ${ }^{c}$ Limited experience exists for lixisenatide in people with an eGFR from 15 to $30 \mathrm{ml} / \mathrm{min} / 1.73 \mathrm{~m}^{2}$. BID twice daily, EMA European Medicines Agency, FDA U.S. Food and Drug Administration, $Q W$ once weekly, SmPC Summary of Product Characteristics, USPI U.S. Prescribing Information

usually initiated with a single oral agent, usually metformin, combined with lifestyle modifications [15]. If HbA1c remains elevated, metformin treatment is followed by sequential addition of oral agents before intensification to injectables in a stepwise approach. Although the primary goal of diabetes management is to 
reduce glycemia and diabetes-related complications, special consideration needs to be taken in people living with compromised renal function. For example, metformin is regarded as contraindicated if eGFR $<30 \mathrm{ml} / \mathrm{min} / 1.73 \mathrm{~m}^{2}$ due to the increased risk of hypoglycemia $[2,67]$.

In 2020, the ADA provided a revision to the Standards of Medical Care in Diabetes with updated guidelines recommending the use of SGLT2i and GLP-1 RAs to treat people living with T2DM and CKD independently of baseline A1C, individualized A1C target, or metformin use [68] (summarized in Fig. 2). These revised changes take into consideration the latest trial findings on SGLT2i and GLP-1 RA and suggest that these medications are the preferred option for people when CKD predominates, independent of HbA1c. If CKD is the predominant condition, the recommendation is to start with an SGLT2i with evidence of reducing CKD progression, assuming eGFR is adequate. If SGLT2i is not tolerated or contraindicated, or if eGFR is less than adequate $\left(<30 \mathrm{ml} / \mathrm{min} / 1.73 \mathrm{~m}^{2}\right)$, then a GLP-1 RA is recommended.

The KDIGO 2020 Clinical Practice Guideline for Diabetes Management Chronic Kidney Disease recommend that people living with T2DM and CKD with eGFR $>30 \mathrm{ml} / \mathrm{min} / 1.73 \mathrm{~m}^{2}$ should receive metformin and SGLT2i (Fig. 2). For those who do not achieve glycemic targets with lifestyle therapy, metformin, and SGLT2i, or who cannot tolerate these agents, whether due to adverse events or because other restrictions apply, other medications are recommended. Of these, GLP-1 RAs are generally preferred because of their demonstrated cardiovascular benefits and potential for improved renal outcomes [2]. In addition, GLP-1 RAs are particularly effective in reducing HbA1c, which is especially relevant as HbA1c levels $\geq 6.5 \%$ have been shown to be associated with increased incidence of microvascular complications [69] while it is challenging to achieve HbA1c levels $<6.5 \%$ with other treatments without increasing the risk of hypoglycemia.

The Lancet Commission on Diabetes recently performed a comprehensive analysis of available data on diabetes care to provide a summary of the best evidence for effectively managing diabetes [70]. Of the key messages provided in their summary, the commission states that SGLT2i and GLP-1 RA therapies can reduce cardiovascular-renal diseases and all-cause death by up to $40 \%$ in people living with T2DM, independently of their effect on lowering blood glucose concentration.

Should a physician decide that a GLP-1 RA would benefit their patient, the next challenge is deciding upon which to prescribe as there are a variety of GLP-1 RAs with regulatory approval in U.S. and European markets, each with different profiles in relation to duration of action (short-acting vs. long-acting), indications (monotherapy and/or combined therapy), timing and ease of dosing, efficacy, and tolerability [71-73]. The variation in profiles means that GLP-1 RAs can be used for treating most stages of CKD, although as described above, there is an exception for people with ESRD $(<15 \mathrm{ml} / \mathrm{min} /$ $1.73 \mathrm{~m}^{2}$ or on dialysis) that is dependent on the prescribing information set by regulators. According to the U.S. and European prescribing information, the majority of GLP-1 RAs can be used without dose adjustments in people with mild (eGFR $60-89 \mathrm{ml} / \mathrm{min} / 1.73 \mathrm{~m}^{2}$ ) or moderate (eGFR $30-59 \mathrm{ml} / \mathrm{min} / 1.73 \mathrm{~m}^{2}$ ) renal impairment. The use of exenatide and its analog, lixisenatide, both GLP-1RAs that cannot be metabolized in circulation and must be cleared renally, is more restricted depending on the CKD grade and prescribing information set by regulators. Currently, dulaglutide, semaglutide, and liraglutide are the only GLP-1 RAs recommended by the European Medicines Agency (EMA) without any dose adjustment in people living with mild, moderate, or severe renal impairment (eGFR $\left.\geq 15 \mathrm{ml} / \mathrm{min} / 1.73 \quad \mathrm{~m}^{2}\right)$ $[65,66,74]$. Figure 5 summarizes the use of GLP-1 RAs in people with renal impairment that is based on either the FDA-approved U.S. prescribing information or the EMA-approved summary of product characteristics.

\section{Recommendations when Combining a GLP-1 RA with Other Glucose-Lowering Medication}

In general, GLP-1 RAs are indicated for use in combination with metformin and with oral 
glucose-lowering agents, including SGLT2i, when glycemic control is not achieved $[75,76]$. When metformin is considered unsuitable as therapy due to intolerance or contraindications, or if there is inadequate glycemic control, several GLP-1 RAs are indicated as monotherapy, including liraglutide, dulaglutide, and semaglutide.

\section{General Recommendations on the Use of a GLP-1 RA Add-on to Insulin}

Basal insulin is effective in reducing fasting blood glucose but is associated with a high risk of hypoglycemia and weight gain [77]. In the revised ADA guidelines, GLP-1 RAs are prioritized as the first injectable glucose-lowering medications ahead of insulin if HbA1c is above the individual target [15]. When compared to insulin, GLP-1 RAs have shown the same or even more efficacy in lowering HbA1c in headto-head trials, with lower risk of hypoglycemia [78-80]. Additional benefits of GLP-1 RA use over insulin include weight reduction, rather than weight gain, which is associated with insulin use, and for GLP-1 RAs administrated weekly, less frequent injections [81].

If HbA1c remains elevated after treatment with GLP-1 RA, basal insulin can be added as adjuvant to the treatment regimen [15] Several meta-analyses of randomized controlled trials found that adding GLP-1 RA to basal insulin led to decreased HbA1c, weight loss, and a lower rate of hypoglycemia when compared to basal bolus insulin [79, 80, 82-84]. Caution needs to be exercised when combining a GLP-1 RA and insulin and, in most cases, the insulin dose needs to be adjusted. Based on reported evidence, the dose of basal insulin should be reduced by $10 \%$, and a decrease of prandial insulin by $30-40 \%$ is recommended when starting concomitant treatment with the addition of a GLP-1 RA [85]. Recently, injection devices that deliver both GLP-1 RA and basal insulin simultaneously have become available, which may have additional benefits, such as improved adherence [86]. Although there is an increased risk of gastrointestinal side effects along with increased costs when adding a GLP-1
RA to the therapeutic regimen, this combination therapy has been shown as an offset to the weight gain observed with insulin therapy [87].

\section{Treatment Decisions: GLP-1 RA, SGLT2i, or Both?}

Both GLP-1 RAs and SGLT2i are recommended after metformin in the treatment of T2DM, as both are associated with renal and cardiovascular disease benefits, a low risk for hypoglycemia, improved glycemia efficacy, and weight loss [15]. Guidelines provided by KDIGO recommend metformin with SGLT2i as first-line therapy in people with eGFR $>30 \mathrm{ml} / \mathrm{min} / 1.73$ $\mathrm{m}^{2}$ [2], with a GLP-1 RA as the preferred agent if additional therapy is needed for glycemic control. The preference for SGLT2 $\mathrm{i}$ is due to more robust evidence regarding renal outcomes. Based on the results of the CREDENCE study [88], canagliflozin is currently allowed in people with eGFR $>30 \mathrm{ml} / \mathrm{min} / 1.73 \mathrm{~m}^{2}$ if they have an albuminuria/creatinine ratio $>300 \mathrm{mg} / \mathrm{g}$ [89]. Similarly, as a result of the positive findings from the recent DAPA-CKD trial [90], dapagliflozin is now indicated for the treatment of $\mathrm{CKD}$, and can be initiated if eGFR $\geq 25 \mathrm{ml} / \mathrm{min} /$ $1.73 \mathrm{~m}^{2}$. The higher cost of GLP-1 RAs may also be a factor in this choice [91]. For people living with T2DM and CKD who (1) do not achieve glycemic targets with lifestyle intervention, metformin, and SGLT2i, (2) cannot take these medications due to intolerances, or (3) have eGFR $<30 \mathrm{ml} / \mathrm{min} / 1.73 \mathrm{~m}^{2}$, GLP-1 RAs are the preferred agent [2]. As GLP-1 RAs are contraindicated for people with gastrointestinal disease, pancreatitis, or a family history of mutations in multiple endocrine neoplasia type 2/medullary thyroid carcinoma (MEN2/MTC), SGLT2i is the preferred treatment for these patients groups. For people at risk of lower limb ulcerations and neuropathy, GLP-1 RAs are recommended over SGLT2i. Although the findings in the CANVAS trial showed a higher risk of amputation when taking canafliglozin compared to placebo [92], no significant difference in the risk of this complication was observed in the CREDENCE study [88]. However, caution is recommended in the use of SGLT2i in people 
with a high risk of amputation or skin ulcers in the lower extremities [89].

Clinical evidence suggests that combined SGLT2i and GLP-1 RA therapy is additive in terms of lowering HbA1c levels, systolic blood pressure, and body weight. In the DURATION-8 study, the SGLT2i dapagliflozin was used in combination therapy with exenatide and showed reductions in $\mathrm{HbA1c}$, systolic blood pressure, and blood glucose, with improved weight loss, when compared to monotherapy [93]. More recently in AWARD-10, the addition of dulaglutide to an SGLT2i also resulted in weight loss, reduced $\mathrm{HbA1c}$, and lower systolic blood pressure [94]. Although combined therapy is still not common practice because of the relatively recent regulatory approval, these studies highlight the potential of dual GLP-1 RA + SGLT2i therapy to synergistically reduce cardiovascular disease and decelerate renal decompensation [75].

\section{Adverse Events, Side Effects, and Safety Considerations}

Overall, GLP-1 RAs are very well tolerated considering their high efficacy in controlling glycemia and the net effect they exert on multiple organ systems (Fig. 3). The adverse events associated with GLP-1 RA use are generally mild and include nausea and vomiting. In addition, there are precautions for their use in people with pancreatitis and diabetic retinopathy, the incidence of which is generally increased in T2DM. Based on several studies, it appears that GLP-1 RAs are safe and effective regardless of renal function status. In a post-hoc analysis of AWARD-11, the effect of dulaglutide treatment was associated with consistent safety and efficacy patterns regardless of their renal function status at baseline, with no more gastrointestinal adverse effects nor hypoglycemic events in those subjects with lower renal function [95]. In a post-hoc analysis of LEADER, the use of liraglutide in those with CKD was safe, with no difference in the frequency of serious adverse events between those participants with and without CKD [96]. More detail on adverse events, plus information on side effects and safety considerations, is provided below and summarized in Table 2.

\section{Gastrointestinal Adverse Events}

Of the adverse effects reported during GLP-1 RA clinical trials, gastrointestinal symptoms were the most frequent, with nausea and diarrhea very common, and vomiting, constipation, abdominal pain, and dyspepsia considered to be relatively common [97]. These symptoms are primarily due to the mode of action of GLP-1 RAs on the gut, as a GLP-1 may directly or indirectly regulate electrolyte and fluid homeostasis by influencing feeding and drinking behavior as well as electrolyte transport in the kidneys and gastrointestinal tract [25]. Ensuring adequate hydration is therefore an important consideration with GLP-1 RA treatment, as is recommended by the label, particularly for people with renal impairment, as dehydration is known to be associated with renal dysfunction [98]. Individuals should seek medical attention if they have prolonged nausea or vomiting, or an inability to take in fluids. Both nausea and vomiting are usually transient and of mild-tomoderate severity, with the frequency more pronounced at the beginning of treatment and people developing a tolerance over time [99]. Adherence to GLP-1 RA therapy may be improved by slowing dose escalation, as per label instructions, and setting patient expectations for possible gastrointestinal adverse outcomes that should subside over time. Close monitoring by the primary care physician is important for effective management of these effects.

Precaution for Use in People with Pancreatitis A retrospective analysis of the US FDA's database of reported adverse events from 2004 to 2009 found exenatide increased the odds ratio (OR) for reported pancreatitis by tenfold compared with other therapies [100]. In contrast, recent meta-analyses suggest that GLP-1 RA use does not increase the risk of pancreatitis and/or pancreatic cancer, compared to placebo and/or other treatments [101-103]. From a practical standpoint, people should be informed of the characteristic symptoms of acute pancreatitis, 
Table 2 General recommendations

General recommendations
Inform individuals that if gastrointestinal symptoms
appear they are generally mild or moderate in severity
and disappearance over time is common. Recommend
that individuals avoid administering a GLP-1 RA
close to a large or high-fat meal because doing so is
likely to cause nausea. Consider progressive dose
escalation
Individuals treated with GLP-1 RA should be advised of
the potential risk of dehydration, particularly in
relation to gastrointestinal adverse reactions. and take
precautions to avoid fluid depletion
Individuals should be informed of the symptoms of
acute pancreatitis. Discontinue if pancreatitis is
suspected and do not restart if confirmed
Monitor blood pressure in individuals with high dose of
diuretics and normal-to-low blood pressure
In people with concomitant use of sulfonylureas or
insulin, consider reducing the dose of sulphonylurea
or insulin to reduce the risk of hypoglycemia

and treatment with GLP-1 RA should be discontinued if pancreatitis is suspected and not restarted if confirmed. In the absence of signs and symptoms, elevations in pancreatic enzymes alone are not predictive of acute pancreatitis.

\section{Precaution for Use in People with Diabetic Retinopathy}

The prevalence of both CKD and diabetic retinopathy, a microvascular complication of diabetes, is known to increase proportionally to T2DM duration [47]. In LEADER, there was a higher, albeit non-significant, rate of adverse retinal events with liraglutide compared with placebo (HR 1.15, 95\% CI 0.87-1.52; $p=0.33$ ) [26]. In the SUSTAIN-6 trial, semaglutide was associated with a significant increased risk of diabetic retinopathy complications, including vitreous hemorrhage, blindness, or conditions requiring treatment with an intravitreal agent or photocoagulation (HR 1.76, 95\% CI 1.11-2.78) [27]. Conversely, population studies have found no association between increased risk of diabetic retinopathy and GLP-1 RA use $[104,105]$, with a low odds ratio observed for exenatide (OR 0.16), liraglutide (OR 0.18), albiglutide (OR 0.09), and dulaglutide (OR 0.11) [106]. In addition, recent clinical evidence from the AngioSafe T2DM Study demonstrated no association between GLP-1 RAs and severe diabetic retinopathy [107], suggesting that GLP-1 RA does not have a causal influence on retinopathy independent of glucose lowering. The general consensus is that any increased risk of retinopathy with GLP-1 RA treatment is likely to be related to the abrupt improvement in glycemic control [108], a phenomenon similar to that reported for other neuropathological complications [109].

\section{Natriuresis and Diuresis}

Studies in people living with T2DM and obesity have shown that GLP-1 RA administration can induce diuresis and natriuresis $[110,111]$ that likely contribute to the renoprotective effects of GLP-1 RA. The diuretic and natriuretic effects of GLP-1 are mediated through downregulation of sodium-hydrogen exchanger 3 (NHE3) activity in the renal proximal tubule that consequently affects renal hemodynamics [112]. Although a decrease in systolic blood pressure is observed with GLP-1 RAs (ranging from $-1.84 \mathrm{mmHg}$ [95\% CI -3.48 to -0.20$]$ to $-4.60 \mathrm{mmHg}$ [95\% CI -7.18 to -2.03 ]) [113], the possibility of requiring adjustment of simultaneous diuretic treatment should be considered.

\section{Hypoglycemia}

Despite having a pronounced anti-hyperglycemic effect, GLP-1 RAs are not typically associated with hypoglycemia when used as monotherapy. Caution is advised, with dose reduction recommended in some cases, when they are combined with a sulphonylurea or insulin as the risk of hypoglycemia is higher. In clinical trials examining GLP-1 RA in combination with a sulphonylurea (with or without metformin) or insulin, the incidence of hypoglycemia was low overall, but increased when 
compared with placebo [114]. When GLP-1 RAs are not used concomitantly with a sulphonylurea or insulin, routine glucose monitoring is unnecessary due to the low risk of developing hypoglycemia.

\section{Weight Loss}

In addition to improving glycemic control, GLP-1 RAs demonstrate a benefit on body weight. This is an important treatment aspect, as weight reduction most likely plays an important role in the prevention and reduced progression of $\mathrm{CKD}$, an association demonstrated in people with macroalbuminuria having undergone bariatric surgery [115]. Data from an early meta-analysis of 18 trials provided evidence that in people living with T2DM, GLP1 RAs promote a mean weight loss of $2.8 \mathrm{~kg}$ $(-3.4$ to $-2.3 \mathrm{~kg})$ [116]. Weight loss varies depending on the dose and type of medication, with differences observed in head-to-head studies [117]. In SUSTAIN-7, a study comparing semaglutide to dulaglutide in patients with inadequately controlled T2DM, a greater reduction in body weight was observed with $0.5 \mathrm{mg}$ semaglutide $(4.6 \mathrm{~kg}$, standard error [SE] 0.28 ) compared with $0.75 \mathrm{mg}$ dulaglutide $(2.3 \mathrm{~kg}, \mathrm{SE} 0.27)$ (estimated treatment difference [ETD] $-2.26 \mathrm{~kg}, 95 \%$ CI -3.02 to -1.51 ; $p<0.0001)$ and with $1.0 \mathrm{mg}$ semaglutide $(6.5 \mathrm{~kg}, \quad$ SE 0.28$)$ compared with $1.5 \mathrm{mg}$ dulaglutide $(3.0 \mathrm{~kg}, \mathrm{SE} 0.27)$ (ETD $-3.55 \mathrm{~kg}$, $95 \% \mathrm{CI}-4.32$ to $-2.78 ; p<0.0001)$ [118] at 40 weeks. Significant reductions in body weight are observed with $3.0 \mathrm{mg}$ and $4.5 \mathrm{mg}$ dulaglutide, doses which have been recently approved for people living with T2DM who are taking metformin but experiencing inadequate glycemic control $[66,119]$. In the AWARD-11 trial, the efficacy and safety of $3.0 \mathrm{mg}$ and $4.5 \mathrm{mg}$ dulaglutide was evaluated at 36 and 52 weeks; the results also demonstrated that these doses led to significant reductions in body weight. Specifically, with $4.5 \mathrm{mg}$ dulaglutide, the weight reduction was $5.0 \mathrm{~kg}$ at 52 weeks of treatment [120]. Compared with the $1.5 \mathrm{mg}$ dulaglutide group, body weight was significantly decreased in the $3.0 \mathrm{mg}$ (ETD $-0.9,95 \% \mathrm{CI}-1.4$ to $-0.4 \mathrm{~kg} ; p<0.05$ and $4.5 \mathrm{mg}$ (ETD $-1.6,95 \%$
CI -2.1 to $-1.1 \mathrm{~kg} ; \quad p<0.001)$ dulaglutide groups at 36 weeks.

\section{General Practical Considerations}

\section{Patient-centered Care}

Patient-centered care in the treatment of diabetes is considered to be essential in effective disease management. People who are more involved in their treatment decisions and have a better understanding of the treatment strategy are more likely to be satisfied with their healthcare [121], while a lack of shared decision-making between patient and prescriber can affect patient satisfaction and may result in non-adherence [122]. These factors are reflected in the joint ADA-EASD guidelines, which place a focus on putting the patient at the center of the treatment paradigm and consider that shared decision-making between patient and provider is essential to create an effective management plan [68]. An emphasis is placed on assessing the patient's individual factors and engaging the patient prior to creation of a management plan. Once the patient consents to the plan, the next steps involve implementation, routine monitoring and support, and review of the plan. It is essential that people are involved in treatment decisions as this can influence how likely they are to continue taking a medication, which can, in turn, affect treatment success.

Considering the large variety of therapies available, each with different attributes and mechanisms of action, along with the heterogenous nature of $\mathrm{T} 2 \mathrm{DM}$, the treatment landscape is understandably complicated. An important factor in helping healthcare professionals and their patients decide on the best medication for the individual is determining patient preference on the frequency (daily vs. weekly) and route of administration (injectable vs. oral), as well as medication costs. In circumstances where patients cover the cost of treatment, where reimbursement is restricted, or when insurance coverage is limited, the financial expense may influence selection of GLP-1 RA therapy [123]. In a recent review of GLP-1 RA patient preferences, important 
attributes driving patient choice included dose frequency, device characteristics (including type of device and needle size), change in HbA1c, and adverse event profile [124].

\section{Dose Frequency}

The recommended dosages and administration requirements for each of the GLP-1 RAs are described in greater detail elsewhere [73]. Briefly, the first GLP-1RA started with administration twice-daily (BID; exenatide BID) followed by once-daily (lixisenatide and liraglutide) and then once-weekly (QW; semaglutide, exenatide and dulaglutide). A summary of the dosing characteristics for currently available GLP-1 RAs is summarized in Table 3. As anticipated, patient preference is towards GLP-1 RA profiles associated with less frequent dosing, with once-weekly preferred to once-daily, with the latter preferred over twicedaily [123-125].

\section{Injection Device Characteristics}

The GLP-1 RA injection devices consist of either a single-use or multi-dose pen that varies by needle size and thickness, which can be factors in predicting patient preference [125] (Table 4). Injections are subcutaneous and therefore tend to be less painful than intramuscular injections, particularly as the needles are smaller. The pen injectors are pre-filled, which is more convenient than carrying bottles or syringes. The complexity of dose regimens, the patient's perception of administration, and fear of injections may affect the rate of commencing injectable treatment. Understanding the characteristics and features of these devices can therefore aid both physicians and their patients in selecting the most appropriate agent.

Daily formulations of GLP-1 RAs, including exenatide BID, liraglutide, and lixisenatide, require dose selection and attachment of a disposable needle each time the injection device is to be used. Both prolonged-release exenatide QW and dulaglutide are weekly formulations that come in single-use devices and do not require dose selection, while semaglutide comes in a multi-dose pen where the specific dose needs to be set by the user. An older version of the exenatide QW device consists of a pre-filled pen with two chambers containing exenatide powder and solvent that require reconstitution. A newer device is now available that features a pre-attached hidden needle with automatic dose administration that requires $15 \mathrm{~s}$ of mixing before administration [126]. The dulaglutide device is ready to use and includes a hidden, pre-attached needle with dose selection or reconstitution not required, which allows for greater ease of use [66].

In an uncontrolled study of 214 people living with T2DM, 99\% of participants considered the single-dose pen "easy" or "very easy" to use [127]. In a separate study that evaluated patient perceptions of the injection devices for liraglutide and dulaglutide, the dulaglutide device was associated with a slightly higher score for ease of use and convenience [128]. Patient preferences between liraglutide and twice-daily exenatide BID were also evaluated, with $96 \%$ of respondents reporting a preference for the liraglutide device compared to that of exenatide [129]. The PREFER study was an open-label, multicenter, randomized, crossover study assessing patient preference for dulaglutide and semaglutide injection devices [130]. Participants with T2DM preferred the dulaglutide injection device to the semaglutide injection device [130]. An important consideration is that, if people prefer a device, they may be more willing to use the medication, potentially resulting in improved health outcomes.

\section{Route of Administration}

The majority of GLP-1 RAs are delivered via injection although an oral formulation has recently become commercially available [131]. While oral administration is less invasive than injection, a recent study indicated no difference in preference between oral semaglutide and dulaglutide [132]. However, it is worth considering that routes of administration cannot be easily compared as dose frequency and specific details of the treatment process administration can impact patient preference. From a patient burden standpoint, people living with advanced CKD take a number of oral medications and may prefer a once-weekly injection to an additional daily oral medication. The once-weekly 


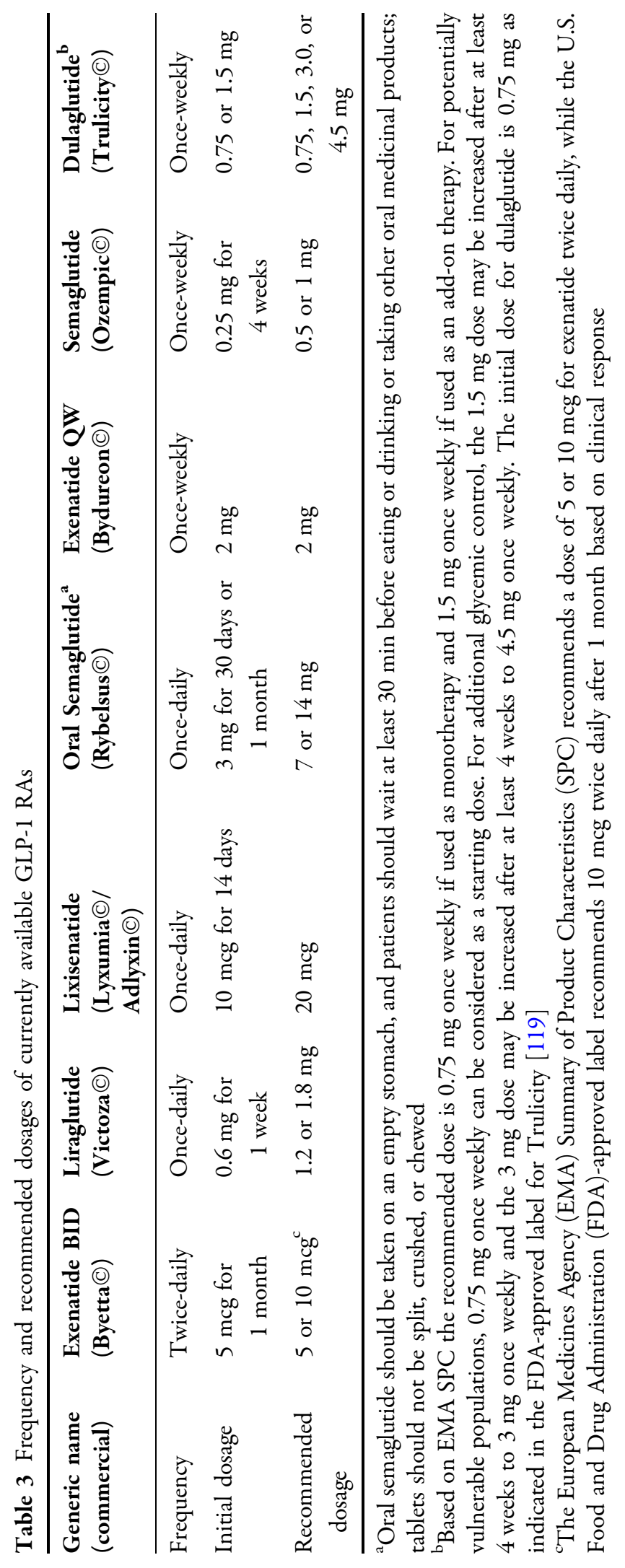


Table 4 Administration characteristics of currently approved GLP-1 RA prefilled pen devices

\begin{tabular}{|c|c|c|c|c|c|c|}
\hline $\begin{array}{l}\text { Generic name } \\
\text { (commercial) }\end{array}$ & $\begin{array}{l}\text { Exenatide twice } \\
\text { daily (Byetta } \odot \text { ) }\end{array}$ & $\begin{array}{l}\text { Liraglutide } \\
(\text { Victoza } \odot \text { ) }\end{array}$ & $\begin{array}{l}\text { Lixisenatide } \\
(\text { Lyxumia } \odot / \\
\text { Adlyxin } \odot \text { ) }\end{array}$ & $\begin{array}{l}\text { Exenatide } \\
\text { QW } \\
\text { (Bydureon } \odot \text { ) }\end{array}$ & $\begin{array}{l}\text { Dulaglutide } \\
\text { (Trulicity } \odot \text { ) }\end{array}$ & $\begin{array}{l}\text { Semaglutide } \\
\text { (Ozempic } \subseteq \text { ) }\end{array}$ \\
\hline $\begin{array}{l}\text { Is reconstitution } \\
\text { required? }\end{array}$ & No & No & No & Yes & No & No \\
\hline $\begin{array}{l}\text { Is dose } \\
\text { administration } \\
\text { automatic? }\end{array}$ & No & No & No & $\mathrm{Yes}^{\mathrm{a}}$ & Yes & No \\
\hline $\begin{array}{l}\text { Does the device } \\
\text { need to be } \\
\text { primed? }\end{array}$ & Yes & Yes & Yes & No & No & Yes \\
\hline $\begin{array}{l}\text { Does a needle } \\
\text { need to be } \\
\text { attached? }\end{array}$ & Yes & Yes & Yes & No & No & Yes \\
\hline $\begin{array}{l}\text { Is dose selection } \\
\text { required? }\end{array}$ & Yes & Yes & No & No & No & Yes \\
\hline $\begin{array}{l}\text { Is the device for } \\
\text { single use? }\end{array}$ & No & No & No & Yes & Yes & No \\
\hline
\end{tabular}

${ }^{a}$ The current device that delivers exenatide once weekly is the Bydureon BCise $\odot$ pen (AstraZeneca plc, Cambridge, UK) that automatically administers the dose. Previous versions of the pen device do not automatically deliver the dose

injection has received positive patient acceptance [123]; however, shared decision-making between the primary care physician and patient is important for improving patient outcomes.

\section{CONCLUSION}

In summary, there is strong evidence from clinical trials for the use of GLP-1 RAs in the management of T2DM in people living with CKD; however, studies that assess renal outcomes as the primary outcome are needed. The recent position statement by the ADA advocating the use of both SGLT2i and GLP-1 RAs is encouraging, indicating that CKD in T2DM is under the spotlight. As different guidelines exist for nephrologists, cardiologists, endocrinologists, primary care practitioners, pharmacists and nurse practitioners, confusion can arise when there is no consensus on the treatment strategy. Guidelines across these specialties must be written and harmonized for the overall betterment of patient welfare. With the advent of additional GLP-1 RAs, it is critical that the treatment landscape be monitored and reviewed so that healthcare practitioners have the most current information when addressing their patients' needs. The evidence currently available indicates that GLP-1 RA could add to the arsenal available to address persistent gaps in the care of people living with T2DM with, or at the risk of, developing CKD and to reduce the residual renal risk present in those who have already developed CKD.

This article is based on previously conducted studies and does not contain any studies with human participants or animals performed by any of the authors. 


\section{ACKNOWLEDGEMENTS}

This article is distributed under the terms of the Creative Commons Attribution Non-Commercial 4.0 International License (http:// creativecommons.org/licenses/by-nc/4.0/), which permits any non-commercial use, distribution, and reproduction in any medium, provided you give appropriate credit to the original author(s) and the source, provide a link to the Creative Commons license, and indicate if changes were made.

Funding. This work and associated article processing charges were supported by Eli Lilly and Company. All authors had full access to all of the data in this study and take complete responsibility for the integrity of the data and accuracy of the data analysis. The sponsor funded the Rapid Service fee and the Open Access fee.

\section{Medical Writing and Editorial Assis-} tance. The authors would like to thank Dr. Róise Ella McGovern for medical writing assistance and administrative support during the preparation of this manuscript. Editorial support was provided by Syneos Health and the infographic was developed by Research Square. Support for this assistance was funded by Eli Lilly and Company.

Authorship. All named authors meet the International Committee of Medical Journal Editors (ICMJE) criteria for authorship for this article, take responsibility for the integrity of the work as a whole and have given their approval for this version to be published.

Author Contributions. José Luis Górriz provided expert clinical opinion and critical revision of the manuscript for important intellectual content and has helped establish the structure and contents of the manuscript. Irene Romera: conception and design of the work; critical revision of the manuscript for important intellectual content. Amelia Cobo: conception and design of the work; critical revision of the manuscript for important intellectual content. Phillipe O'Brien: conception and design of the work; performed the literature search; drafted the manuscript, including figures and tables. Juan Francisco Merino-Torres: provided expert clinical opinion and critical revision of the manuscript for important intellectual content. All authors approved the final version of the manuscript. The conception, design, interpretation of the results, writing, review, and approval of the submitted manuscript were made by all authors.

Disclosures. José Luis Górriz has served as consultant to Boehringer Ingelheim, Mundipharma, AstraZeneca, and Novo Nordisk and has received speaker honoraria from Boehringer Ingelheim, Mundipharma, AstraZeneca, Novo Nordisk, Novartis, and Eli Lilly and Company. Irene Romera, and Amelia Cobo are employees and minor stockholders of Eli Lilly and Company. Phillipe O'Brien was an employee of Eli Lilly and Company at the time of submission. Francisco Merino-Torres has nothing to disclose.

Compliance with Ethics Guidelines. This article is based on previously conducted studies and does not contain any studies with human participants or animals performed by any of the authors.

Data Availability. Sharing is not applicable to this article as no datasets were generated or analyzed during the current study.

Open Access. This article is licensed under a Creative Commons Attribution-NonCommercial 4.0 International License, which permits any non-commercial use, sharing, adaptation, distribution and reproduction in any medium or format, as long as you give appropriate credit to the original author(s) and the source, provide a link to the Creative Commons licence, and indicate if changes were made. The images or other third party material in this article are included in the article's Creative Commons licence, unless indicated otherwise in a credit line to the material. If material is not included in the article's Creative Commons licence and your intended use is not permitted by statutory regulation or exceeds the 
permitted use, you will need to obtain permission directly from the copyright holder. To view a copy of this licence, visit http:// creativecommons.org/licenses/by-nc/4.0/.

\section{REFERENCES}

1. Bailey RA, Wang Y, Zhu V, Rupnow MFT. Chronic kidney disease in US adults with type 2 diabetes: an updated national estimate of prevalence based on Kidney Disease: Improving Global Outcomes (KDIGO) staging. BMC Res Notes. 2014;7:415.

2. Kidney Disease: Improving Global Outcomes Diabetes (KDIGO) Work Group. KDIGO 2020 clinical practice guideline for diabetes management in chronic kidney disease. Kidney Inter, Suppl. 2020;2020(98):S1-115.

3. American Diabetes Association. 11. Microvascular complications and foot care: standards of medical care in diabetes-2021. Diabetes Care. 2021;44: S151-67.

4. Adler AI, Stevens RJ, Manley SE, et al. Development and progression of nephropathy in type 2 diabetes: The United Kingdom Prospective Diabetes Study (UKPDS 64). Kidney Int. 2003;63:225-32.

5. Afkarian M, Sachs MC, Kestenbaum B, et al. Kidney disease and increased mortality risk in type 2 diabetes. J Am Soc Nephrol. 2013;24:302-8.

6. Hill CJ, Fogarty DG. Changing trends in end-stage renal disease due to diabetes in the United kingdom. J Ren Care. 2012;38(Suppl 1):12-22.

7. Foreman KJ, Marquez N, Dolgert A, et al. Forecasting life expectancy, years of life lost, and all-cause and cause-specific mortality for 250 causes of death: reference and alternative scenarios for 2016-40 for 195 countries and territories. Lancet. 2018;392: 2052-90.

8. Bolignano D, Zoccali C. Effects of weight loss on renal function in obese CKD patients: a systematic review. Nephrol Dial Transplant. 2013;28(Suppl 4): iV82-98.

9. Herrera-Gomez F, Asensio-Gonzalez M, GonzalezLopez A, Alvarez FJ. Effects of intensive control of glycemia on clinical kidney outcomes in type 2 diabetes patients compared with standard control: a meta-analysis. Front Pharmacol. 2017;8:845.

10. Wang $\mathrm{K}, \mathrm{Hu} \mathrm{J}$, Luo T, et al. Effects of angiotensinconverting enzyme inhibitors and angiotensin II receptor blockers on all-cause mortality and renal outcomes in patients with diabetes and albuminuria: a systematic review and meta-analysis. Kidney Blood Press Res. 2018;43:768-79.

11. National Kidney Foundation. KDOQI clinical practice guideline for diabetes and CKD: 2012 update. Am J Kidney Dis. 2012;60:850-86.

12. Tuttle KR, Bakris GL, Bilous RW, et al. Diabetic kidney disease: a report From an ADA Consensus Conference. Diabetes Care. 2014;37:2864.

13. Gerich JE, Meyer C, Woerle HJ, Stumvoll M. Renal gluconeogenesis: its importance in human glucose homeostasis. Diabetes Care. 2001;24:382-91.

14. Jardine MJ, Zhou Z, Mahaffey KW, et al. Renal, cardiovascular, and safety outcomes of canagliflozin by baseline kidney function: a secondary analysis of the CREDENCE Randomized Trial. J Am Soc Nephrol. 2020;31:1128-39.

15. American Diabetes Association. 9. Pharmacologic approaches to glycemic treatment: standards of medical care in diabetes-2021. Diabetes Care. 2021;44:S11-24.

16. European Medicines Agency. Summary of Product Characteristics (Jardiance). 2021. https://ec.europa. $\mathrm{eu} /$ health/documents/community-register/2021/ 20211022153282/anx_153282_en.pdf Accessed 12 Nov 2021.

17. U.S. Food and Drug Administration. Jardiance Prescribing Information. https://www.accessdata.fda. gov/drugsatfda_docs/label/2021/ 204629s028s029lbl.pdf Accessed 12 Nov 2021.

18. European Medicines Agency. Summary of product characteristics (Invokana). 2021. https://www.ema. europa.eu/en/documents/product-information/ invokana-epar-product-information_en.pdf Accessed 12 Nov 2021.

19. U.S. Food and Drug Administration. Invokana Prescribing Information. https://www.accessdata.fda. gov/drugsatfda_docs/label/2020/204042s036lbl.pdf Accessed 12 Nov 2021.

20. U.S. Food and Drug Administration. Forxiga Prescribing Information. https://den8dhaj6zs0e. cloudfront.net/50fd68b9-106b-4550-b5d0-12b045 f8b184/0be9cb1b-3b33-41c7-bfc2-04c9f718e442/ Obe9cb1b-3b33-41c7-bfc2-04c9f718e442_viewable_ rendition__v.pdf Accessed 12 Nov 2021.

21. European Medicines Agency. Summary of Product Characteristics (Forxiga). 2021. https://www.ema. europa.eu/en/documents/product-information/for xiga-epar-product-information_en.pdf. Accessed 12 Nov 2021. 
22. Kayaniyil S, Lozano-Ortega G, Bennett HA, et al. A network meta-analysis comparing exenatide once weekly with other GLP-1 receptor agonists for the treatment of type 2 diabetes mellitus. Diabetes Ther. 2016;7:27-43.

23. Scheen AJ. Dulaglutide (LY-2189265) for the treatment of type 2 diabetes. Expert Rev Clin Pharmacol. 2016;9:385-99.

24. Dungan KM, Povedano ST, Forst T, et al. Onceweekly dulaglutide versus once-daily liraglutide in metformin-treated patients with type 2 diabetes (AWARD-6): a randomised, open-label, phase 3, non-inferiority trial. Lancet. 2014;384:1349-57.

25. Muskiet MHA, Tonneijck L, Smits MM, et al. GLP-1 and the kidney: from physiology to pharmacology and outcomes in diabetes. Nat Rev Nephrol. 2017;13:605-28.

26. Marso SP, Daniels GH, Brown-Frandsen K, et al. Liraglutide and cardiovascular outcomes in type 2 diabetes. N Engl J Med. 2016;375:311-22.

27. Marso SP, Bain SC, Consoli A, et al. Semaglutide and cardiovascular outcomes in patients with type 2 diabetes. N Engl J Med. 2016;375:1834-44.

28. Hernandez AF, Green JB, Janmohamed S, et al. Albiglutide and cardiovascular outcomes in patients with type 2 diabetes and cardiovascular disease (Harmony Outcomes): a double-blind, randomised placebo-controlled trial. Lancet. 2018;392:1519-29.

29. Gerstein HC, Colhoun HM, Dagenais GR, et al. Dulaglutide and cardiovascular outcomes in type 2 diabetes (REWIND): a double-blind, randomised placebo-controlled trial. Lancet. 2019;394:121-30.

30. Mann JFE, Orsted DD, Brown-Frandsen K, et al. Liraglutide and renal outcomes in type 2 diabetes. N Engl J Med. 2017;377:839-48.

31. Mann JFE, Hansen T, Idorn T, et al. Effects of onceweekly subcutaneous semaglutide on kidney function and safety in patients with type 2 diabetes: a post-hoc analysis of the SUSTAIN 1-7 randomised controlled trials. Lancet Diabetes Endocrinol. 2020;8:880-93.

32. Gerstein HC, Colhoun HM, Dagenais GR, et al. Dulaglutide and renal outcomes in type 2 diabetes: an exploratory analysis of the REWIND randomised, placebo-controlled trial. Lancet. 2019;394:131-8.

33. Tuttle KR, Lakshmanan MC, Rayner B, et al. Dulaglutide versus insulin glargine in patients with type 2 diabetes and moderate-to-severe chronic kidney disease (AWARD-7): a multicentre, open-label, randomised trial. Lancet Diabetes Endocrinol. 2018;6:605-17.
34. Thomas MC. The potential and pitfalls of GLP-1 receptor agonists for renal protection in type 2 diabetes. Diabetes Metab. 2017;43(Suppl 1):2S20-7.

35. Greco EV, Russo G, Giandalia A, et al. GLP-1 receptor agonists and kidney protection. Medicina (Kaunas). 2019;55:233.

36. Betonico CC, Titan SM, Correa-Giannella ML, Nery M, Queiroz M. Management of diabetes mellitus in individuals with chronic kidney disease: therapeutic perspectives and glycemic control. Clinics (Sao Paulo). 2016;71:47-53.

37. Boye KS, Botros FT, Haupt A, Woodward B, Lage MJ. Glucagon-like peptide-1 receptor agonist use and renal impairment: a retrospective analysis of an electronic health records database in the U.S. population. Diabetes Ther. 2018;9:637-50.

38. U.S. Food and Drug Administration. Guidance for industry: diabetes mellitus-evaluating cardiovascular risk in new antidiabetic therapies to treat type 2 diabetes. 2008. https://www.fda.gov/media/ 71297/download. Accessed 7 July 2021.

39. Pfeffer MA, Claggett B, Diaz R, et al. Lixisenatide in patients with type 2 diabetes and acute coronary syndrome. N Engl J Med. 2015;373:2247-57.

40. Holman RR, Bethel MA, Mentz RJ, et al. Effects of once-weekly exenatide on cardiovascular outcomes in type 2 diabetes. N Engl J Med. 2017;377:1228-39.

41. Husain M, Birkenfeld AL, Donsmark M, et al. Oral semaglutide and cardiovascular outcomes in patients with type 2 diabetes. $\mathrm{N}$ Engl J Med. 2019;381:841-51.

42. Kristensen SL, Rorth R, Jhund PS, et al. Cardiovascular, mortality, and kidney outcomes with GLP-1 receptor agonists in patients with type 2 diabetes: a systematic review and meta-analysis of cardiovascular outcome trials. Lancet Diabetes Endocrinol. 2019;7:776-85.

43. Bethel MA, Mentz RJ, Merrill P, et al. Renal outcomes in the EXenatide study of cardiovascular event lowering (EXSCEL). Diabetes. 2018;67:522-9.

44. Muskiet MHA, Tonneijck L, Huang Y, et al. Lixisenatide and renal outcomes in patients with type 2 diabetes and acute coronary syndrome: an exploratory analysis of the ELIXA randomised, placebo-controlled trial. Lancet Diabetes Endocrinol. 2018;6:859-69.

45. Gerstein HC, Colhoun HM, Dagenais GR, et al. Dulaglutide and renal outcomes in type 2 diabetes: an exploratory analysis of the REWIND randomised, placebo-controlled trial.Lancet. 2019;394:131-8. 
46. Mann JFE, Fonseca V, Mosenzon O, et al. Effects of liraglutide versus placebo on cardiovascular events in patients with type 2 diabetes mellitus and chronic kidney disease: results from the LEADER trial. Circulation. 2018;138:2908-18.

47. Park HC, Lee YK, Cho A, et al. Diabetic retinopathy is a prognostic factor for progression of chronic kidney disease in the patients with type 2 diabetes mellitus. PLoS ONE. 2019;14:e0220506.

48. Davies MJ, Bain SC, Atkin SL, et al. Efficacy and safety of liraglutide versus placebo as add-on to glucose-lowering therapy in patients with type 2 diabetes and moderate renal impairment (LIRARENAL): A randomized clinical trial. Diabetes Care. 2016;39:222-30.

49. Bethel MA, Mentz RJ, Merrill P, et al. Microvascular and cardiovascular outcomes according to renal function in patients treated with once-weekly exenatide: insights from the EXSCEL Trial. Diabetes Care. 2020;43:446-52.

50. Shaw JE, Botros FT, Malik R, et al. Effect of dulaglutide on kidney function-related outcomes in type 2 diabetes: post hoc analysis from the REWIND Trial. Diabetes. 2020;69:356-OR.

51. ClinicalTrials.gov. A heart disease study of semaglutide in patients with type 2 diabetes (SOUL) https://clinicaltrials.gov/ct2/show/NCT03914326 Accessed 22 Mar 2021.

52. ClinicalTrials.gov. A research study to see how semaglutide works compared to placebo in people with type 2 diabetes and chronic kidney disease (FLOW) https://clinicaltrials.gov/ct2/show/ NCT03819153 Accessed 22 Mar 2021.

53. Cefalu WT, Kaul S, Gerstein HC, et al. Cardiovascular outcomes trials in type 2 diabetes: where do we go from here? Reflections from a diabetes care editors' expert forum. Diabetes Care. 2018;41: 14-31.

54. Natale P, Gutman T, Howell M, et al. Recruitment and retention in clinical trials in chronic kidney disease: report from national workshops with patients, caregivers and health professionals. Nephrol Dial Transplant. 2020;35:755-64.

55. Hiramatsu T, Ozeki A, Ishikawa H, Furuta S. Long term effects of liraglutide in japanese patients with type 2 diabetes among the subgroups with different renal functions: results of 2-year prospective study. Drug Res. 2017;67:640-6.

56. von Scholten BJ, Persson F, Rosenlund S, et al. The effect of liraglutide on renal function: a randomized clinical trial. Diabetes Obes Metab. 2017;19:239-47.
57. Imamura S, Hirai K, Hirai A. The glucagon-like peptide-1 receptor agonist, liraglutide, attenuates the progression of overt diabetic nephropathy in type 2 diabetic patients. Tohoku J Exp Med. 2013;231:57-61.

58. Tonneijck L, Muskiet $\mathrm{MH}$, Smits MM, et al. Glomerular hyperfiltration in diabetes: mechanisms, clinical significance, and treatment. J Am Soc Nephrol. 2017;28:1023-39.

59. Morieri ML, Frison V, Rigato M, et al. Effectiveness of dulaglutide in the real world and in special populations of type 2 diabetic patients. J Clin Endocrinol Metab. 2020;105:e2617-25.

60. Hecking M, Sharif A, Eller K, Jenssen T. Management of post-transplant diabetes: immunosuppression, early prevention, and novel antidiabetics. Transpl Int. 2021;34:27-48.

61. Thangavelu T, Lyden E, Shivaswamy V. A retrospective study of glucagon-like peptide 1 receptor agonists for the management of diabetes after transplantation. Diabetes Ther. 2020;11:987-94.

62. Kukla A, Hill J, Merzkani M, et al. The use of GLP1R agonists for the treatment of type 2 diabetes in kidney transplant recipients. Transplant Direct. 2020;6:e524.

63. Liou JH, Liu YM, Chen CH. Management of diabetes mellitus with glucagonlike peptide-1 agonist liraglutide in renal transplant recipients: a retrospective study. Transplant Proc. 2018;50:2502-5.

64. Singh P, Pesavento TE, Washburn K, Walsh D, Meng $S$. Largest single-centre experience of dulaglutide for management of diabetes mellitus in solid organ transplant recipients. Diabetes Obes Metab. 2019;21:1061-5.

65. European Medicines Agency. Summary of product characteristics (Ozempic). 2019. https://www.ema. europa.eu/en/documents/product-information/ ozempic-epar-product-information_en.pdf. Accessed 22 Mar 2021.

66. European Medicines Agency. Summary of product characteristics (Trulicity). 2019. https://www.ema. europa.eu/en/documents/product-information/ trulicity-epar-product-information_en.pdf. Accessed 22 Mar 2021.

67. Inzucchi SE, Lipska KJ, Mayo H, Bailey CJ, McGuire DK. Metformin in patients with type 2 diabetes and kidney disease: a systematic review. JAMA. 2014;312:2668-75.

68. American Diabetes Association. 9. Pharmacologic approaches to glycemic treatment: standards of 
medical care in Diabetes-2020. Diabetes Care. 2020;43:S98-110.

69. Laiteerapong N, Ham SA, Gao Y, et al. The legacy effect in type 2 diabetes: impact of early glycemic control on future complications (The Diabetes \& Aging Study). Diabetes Care. 2019;42:416-26.

70. Chan JCN, Lim LL, Wareham NJ, et al. The Lancet Commission on diabetes: using data to transform diabetes care and patient lives. Lancet. 2021;396: 2019-82.

71. Drucker DJ, Nauck MA. The incretin system: glucagon-like peptide-1 receptor agonists and dipeptidyl peptidase- 4 inhibitors in type 2 diabetes. Lancet. 2006;368:1696-705.

72. Trujillo JM, Nuffer W, Ellis SL. GLP-1 receptor agonists: a review of head-to-head clinical studies. Ther Adv Endocrinol Metab. 2015;6:19-28.

73. Romera I, Cebrian-Cuenca A, Alvarez-Guisasola F, Gomez-Peralta F, Reviriego J. A Review of practical issues on the use of glucagon-like peptide- 1 receptor agonists for the management of type 2 diabetes. Diabetes Ther. 2019;10:5-19.

74. European Medicines Agency. Summary of Product Characteristics (Victoza). 2019. https://www.ema. europa.eu/en/documents/product-information/ victoza-epar-product-information_en.pdf. Accessed 22 Mar 2021.

75. Goncalves E, Bell DSH. Combination treatment of SGLT2 inhibitors and GLP-1 receptor agonists: symbiotic effects on metabolism and cardiorenal risk. Diabetes Ther. 2018;9:919-26.

76. Hinnen D. Glucagon-like peptide 1 receptor agonists for type 2 diabetes. Diabetes Spectr. 2017;30: 202-10.

77. Inzucchi SE, Bergenstal RM, Buse JB, et al. Management of hyperglycemia in type 2 diabetes: a patient-centered approach: position statement of the American Diabetes Association (ADA) and the European Association for the Study of Diabetes (EASD). Diabetes Care. 2012;35:1364-79.

78. Diamant M, Nauck MA, Shaginian R, et al. Glucagon-like peptide 1 receptor agonist or bolus insulin with optimized basal insulin in type 2 diabetes. Diabetes Care. 2014;37:2763-73.

79. Eng C, Kramer CK, Zinman B, Retnakaran R. Glucagon-like peptide-1 receptor agonist and basal insulin combination treatment for the management of type 2 diabetes: a systematic review and metaanalysis. Lancet. 2014;384:2228-34.
80. Maiorino MI, Chiodini P, Bellastella G, et al. Insulin and glucagon-like peptide 1 receptor agonist combination therapy in type 2 diabetes: a systematic review and meta-analysis of randomized controlled trials. Diabetes Care. 2017;40:614-24.

81. Morillas C, D’Marco L, Puchades MJ, et al. Insulin withdrawal in diabetic kidney disease: what are we waiting for? Int J Environ Res Public Health. 2021; 18:5388.

82. de Wit HM, Vervoort GM, Jansen HJ, et al. Liraglutide reverses pronounced insulin-associated weight gain, improves glycaemic control and decreases insulin dose in patients with type 2 diabetes: a 26 week, randomised clinical trial (ELEGANT). Diabetologia. 2014;57:1812-9.

83. Pozzilli P, Norwood P, Jódar E, et al. Placebo-controlled, randomized trial of the addition of onceweekly glucagon-like peptide-1 receptor agonist dulaglutide to titrated daily insulin glargine in patients with type 2 diabetes (AWARD-9). Diabetes Obes Metab. 2017;19:1024-31.

84. Guja C, Frías JP, Somogyi A, et al. Effect of exenatide QW or placebo, both added to titrated insulin glargine, in uncontrolled type 2 diabetes: The DURATION-7 randomized study. Diabetes Obes Metab. 2018;20:1602-14.

85. Artigas CF, Stokes V, Tan GD, Theodorakis MJ. Insulin dose adjustments with add-on glucagon-like peptide-1 receptor (GLP-1R) agonists in clinical practice. Expert Opin Pharmacother. 2015;16: 1417-21.

86. Nuffer W, Guesnier A, Trujillo JM. A review of the new GLP-1 receptor agonist/basal insulin fixed-ratio combination products. Ther Adv Endocrinol Metab. 2018;9:69-79.

87. Rosenstock J, Guerci B, Hanefeld M, et al. Prandial options to advance basal insulin glargine therapy: testing lixisenatide plus basal insulin versus insulin glulisine either as basal-plus or basal-bolus in type 2 diabetes: the GetGoal Duo-2 Trial. Diabetes Care. 2016;39:1318-28.

88. Perkovic V, Jardine MJ, Neal B, et al. Canagliflozin and renal outcomes in type 2 diabetes and nephropathy. N Engl J Med. 2019;380:2295-306.

89. European Medicines Agency. Summary of Product Characteristics (Invokana). 2019. https://www.ema. europa.eu/en/documents/product-information/ invokana-epar-product-information_en.pdf. Accessed 22 Mar 2021.

90. Heerspink HJL, Stefansson BV, Correa-Rotter R, et al. Dapagliflozin in patients with chronic kidney disease. N Engl J Med. 2020;383:1436-46. 
91. Luo J, Feldman R, Rothenberger SD, Hernandez I, Gellad WF. Coverage, formulary restrictions, and out-of-pocket costs for sodium-glucose cotransporter 2 inhibitors and glucagon-like peptide 1 receptor agonists in the medicare part D program. JAMA Netw Open. 2020;3:e2020969.

92. Matthews DR, Li Q, Perkovic V, et al. Effects of canagliflozin on amputation risk in type 2 diabetes: the CANVAS Program. Diabetologia. 2019;62: 926-38.

93. Frias JP, Guja C, Hardy E, et al. Exenatide once weekly plus dapagliflozin once daily versus exenatide or dapagliflozin alone in patients with type 2 diabetes inadequately controlled with metformin monotherapy (DURATION-8): a 28 week, multicentre, doubleblind, phase 3, randomised controlled trial. Lancet Diabetes Endocrinol. 2016;4:1004-16.

94. Ludvik B, Frias JP, Tinahones FJ, et al. Dulaglutide as add-on therapy to SGLT2 inhibitors in patients with inadequately controlled type 2 diabetes (AWARD10): a 24-week, randomised, double-blind, placebocontrolled trial. Lancet Diabetes Endocrinol. 2018;6:370-81.

95. Garcia-Perez L-E, Maldonado JM, Ranta KT, Raha S. 673-P: effect of once-weekly dulaglutide 3.0 and 4.5 $\mathrm{mg}$ in patients with different baseline renal function: post-hoc analysis from the award-11 trial. Diabetes. 2021;70:673-P.

96. Mann JFE, Fonseca VA, Poulter NR, et al. Safety of liraglutide in type 2 diabetes and chronic kidney disease. Clin J Am Soc Nephrol. 2020;15:465-73.

97. Sun F, Chai S, Yu K, et al. Gastrointestinal adverse events of glucagon-like peptide-1 receptor agonists in patients with type 2 diabetes: a systematic review and network meta-analysis. Diabetes Technol Ther. 2015;17:35-42.

98. Roncal-Jimenez C, Lanaspa MA, Jensen T, SanchezLozada LG, Johnson RJ. Mechanisms by which dehydration may lead to chronic kidney disease. Ann Nutr Metab. 2015;66(Suppl 3):10-3.

99. Raccah D. Safety and tolerability of glucagon-like peptide-1 receptor agonists: unresolved and emerging issues. Expert Opin Drug Saf. 2017;16: 227-36.

100. Elashoff M, Matveyenko AV, Gier B, Elashoff R, Butler PC. Pancreatitis, pancreatic, and thyroid cancer with glucagon-like peptide-1-based therapies. Gastroenterology. 2011;141:150-6.

101. Storgaard H, Cold F, Gluud LL, Vilsboll T, Knop FK. Glucagon-like peptide-1 receptor agonists and risk of acute pancreatitis in patients with type 2 diabetes. Diabetes Obes Metab. 2017;19:906-8.
102. Cao C, Yang S, Zhou Z. GLP-1 receptor agonists and pancreatic safety concerns in type 2 diabetic patients: data from cardiovascular outcome trials. Endocrine. 2020;68:518-25.

103. Pinto LC, Falcetta MR, Rados DV, Leitao CB, Gross JL. Glucagon-like peptide-1 receptor agonists and pancreatic cancer: a meta-analysis with trial sequential analysis. Sci Rep. 2019;9:2375.

104. Douros A, Filion KB, Yin H, et al. Glucagon-like peptide 1 receptor agonists and the risk of incident diabetic retinopathy. Diabetes Care. 2018;41: 2330-8.

105. Wang T, Hong JL, Gower EW, et al. Incretin-based therapies and diabetic retinopathy: real-world evidence in Older U.S. Adults. Diabetes Care. 2018;41: 1998-2009.

106. Wang T, Lu W, Tang H, et al. Assessing the association between GLP-1 receptor agonist use and diabetic retinopathy through the FDA adverse event reporting system. Diabetes Care. 2019;42:e21-3.

107. Gaborit B, Julla JB, Besbes S, et al. Glucagon-like peptide 1 receptor agonists, diabetic retinopathy and angiogenesis: the AngioSafe Type 2 Diabetes Study. J Clin Endocrinol Metab. 2020;105: e1549-60.

108. Bethel MA, Diaz R, Castellana N, et al. HbA1c change and diabetic retinopathy during GLP-1 receptor agonist cardiovascular outcome trials: a meta-analysis and meta-regression. Diabetes Care. 2021;44:290-6.

109. Gibbons $\mathrm{CH}$, Freeman R. Treatment-induced neuropathy of diabetes: an acute, iatrogenic complication of diabetes. Brain. 2015;138:43-52.

110. Gutzwiller JP, Tschopp S, Bock A, et al. Glucagonlike peptide 1 induces natriuresis in healthy subjects and in insulin-resistant obese men. J Clin Endocrinol Metab. 2004;89:3055-61.

111. Lovshin JA, Barnie A, DeAlmeida A, et al. Liraglutide promotes natriuresis but does not increase circulating levels of atrial natriuretic peptide in hypertensive subjects with type 2 diabetes. Diabetes Care. 2015;38:132-9.

112. Crajoinas RO, Oricchio FT, Pessoa TD, et al. Mechanisms mediating the diuretic and natriuretic actions of the incretin hormone glucagon-like peptide- 1 . Am J Physiol Renal Physiol. 2011;301:F355-63.

113. Sun F, Wu S, Guo S, et al. Impact of GLP-1 receptor agonists on blood pressure, heart rate and hypertension among patients with type 2 diabetes: a systematic review and network meta-analysis. Diabetes Res Clin Pract. 2015;110:26-37. 
114. Filippatos TD, Panagiotopoulou TV, Elisaf MS. Adverse effects of GLP-1 receptor agonists. Rev Diabet Stud. 2014;11:202-30.

115. Shulman A, Peltonen M, Sjostrom CD, et al. Incidence of end-stage renal disease following bariatric surgery in the Swedish Obese Subjects Study. Int J Obes (Lond). 2018;42:964-73.

116. Vilsboll T, Christensen M, Junker AE, Knop FK, Gluud LL. Effects of glucagon-like peptide-1 receptor agonists on weight loss: systematic review and meta-analyses of randomised controlled trials. BMJ. 2012;344:d7771.

117. Madsbad S. Review of head-to-head comparisons of glucagon-like peptide-1 receptor agonists. Diabetes Obes Metab. 2016;18:317-32.

118. Pratley RE, Aroda VR, Lingvay I, et al. Semaglutide versus dulaglutide once weekly in patients with type 2 diabetes (SUSTAIN 7): a randomised, open-label, phase 3b trial. Lancet Diabetes Endocrinol. 2018;6:275-86.

119. U.S. Food and Drug Administration. Trulicity Prescribing Information. https://www.accessdata.fda. gov/drugsatfda_docs/label/2020/125469s033lbl.pdf Accessed 22 Mar 2021.

120. Frias JP, Bonora E, Nevarez Ruiz L, et al. Efficacy and safety of dulaglutide $3.0 \mathrm{mg}$ and $4.5 \mathrm{mg}$ versus dulaglutide $1.5 \mathrm{mg}$ in metformin-treated patients with type 2 diabetes in a randomized controlled trial (AWARD-11). Diabetes Care. 2021;44:765-73.

121. Milky G, Thomas J 3rd. Shared decision making, satisfaction with care and medication adherence among patients with diabetes. Patient Educ Couns. 2020;103:661-9.

122. Pages-Puigdemont N, Mangues MA, Masip M, et al. Patients' perspective of medication adherence in chronic conditions: a qualitative study. Adv Ther. 2016;33:1740-54.

123. Almandoz JP, Lingvay I, Morales J, Campos C. Switching between glucagon-like peptide-1 receptor agonists: rationale and practical guidance. Clin Diabetes. 2020;38:390-402.

124. Thieu VT, Robinson S, Kennedy-Martin T, Boye KS, Garcia-Perez LE. Patient preferences for glucagon- like peptide 1 receptor-agonist treatment attributes. Patient Prefer Adherence. 2019;13:561-76.

125. Hauber AB, Nguyen H, Posner J, Kalsekar I, Ruggles J. A discrete-choice experiment to quantify patient preferences for frequency of glucagon-like peptide-1 receptor agonist injections in the treatment of type 2 diabetes. Curr Med Res Opin. 2016;32:251-62.

126. European Medicines Agency. Summary of Product Characteristics (Bydureon). 2019. https://www.ema. europa.eu/en/documents/product-information/ bydureon-epar-product-information_en.pdf. Accessed 22 Mar 2021.

127. Matfin G, Van Brunt K, Zimmermann AG, Threlkeld $\mathrm{R}$, Ignaut DA. Safe and effective use of the once weekly dulaglutide single-dose pen in injectionnaive patients with type 2 diabetes. J Diabetes Sci Technol. 2015;9:1071-9.

128. Matza LS, Boye KS, Currie BM, et al. Patient perceptions of injection devices used with dulaglutide and liraglutide for treatment of type 2 diabetes. Curr Med Res Opin. 2018;34:1457-64.

129. Polster M, Zanutto E, McDonald S, Conner C, Hammer M. A comparison of preferences for two GLP-1 products-liraglutide and exenatide-for the treatment of type 2 diabetes. J Med Econ. 2010;13: 655-61.

130. Matza LS, Boye KS, Stewart KD, et al. Assessing patient PREFERence between the dulaglutide pen and the semaglutide pen: a crossover study (PREFER). Diabetes Obes Metab. 2020;22:355-64.

131. Pratley R, Amod A, Hoff ST, et al. Oral semaglutide versus subcutaneous liraglutide and placebo in type 2 diabetes (PIONEER 4): a randomised, doubleblind, phase 3a trial. Lancet. 2019;394:39-50.

132. Matza LS, Cutts KN, Stewart KD, et al. Health state utilities associated with treatment process for oral and injectable GLP-1 receptor agonists for type 2 diabetes. Qual Life Res. 2021;30:2033-43.

133. Kidney Disease: Improving Global Outcomes Diabetes Work Group. KDIGO 2012 clinical practice guideline for the evaluation and management of chronic kidney disease. Kidney Int Suppl. 2013;3: 1-150. 